\title{
High-Resolution Topography-Following Chemical Mapping of Ocean Hypoxia by Use of an Autonomous Underwater Vehicle: The Santa Monica Basin Example
}

\author{
ANDREAS F. HOFMANN \\ German Aerospace Center (DLR), Institute of Technical Thermodynamics, Stuttgart, Germany, and Monterey Bay \\ Aquarium Research Institute, Moss Landing, California
}

Peter M. Walz, Hans Thomas, Edward T. Peltzer, and Peter G. Brewer

Monterey Bay Aquarium Research Institute, Moss Landing, California

(Manuscript received 29 November 2012, in final form 18 June 2013)

\begin{abstract}
This paper reports on the execution of a combined chemical sensing/high-resolution terrain-following autonomous underwater vehicle (AUV) survey to explore the fine structure and functional boundaries of the Santa Monica Basin suboxic zone and its relationship to topography. An AUV mapping vehicle is used in a novel configuration - combining the mapping vehicle tail section, with precision inertial navigation and acoustic communications systems, with $\mathrm{CTD} / \mathrm{O}_{2}, \mathrm{NO}_{3}$ sensing, and Gulper water sampling systems. The challenge was to perform a long-distance near-bottom physical/chemical survey in deep water without any intermediate surfacing to disrupt the survey or require the vehicle to surface in areas of heavy ship traffic. Some $210 \mathrm{~km}$ of AUV cruise track at $\approx 10 \mathrm{~m}$ above bottom were accomplished during a 3-day survey. The dissolved oxygen concentration $\left[\mathrm{O}_{2}\right]$ data are combined with temperature $T$, salinity $S$, and hydrostatic pressure $P$ to produce maps of oxygen partial pressure $\mathrm{pO}_{2}$ that help define the limits at which the oceanic supply of $\mathrm{O}_{2}$ can match the $\mathrm{O}_{2}$ demands required to sustain various forms of marine life. The chemical $\mathrm{NO}_{3}$ sensing was included to define the critical $\mathrm{pO}_{2}$ boundary at which $\mathrm{NO}_{3}$ reduction occurs. The combination of a high-resolution terrain-following AUV with chemical sensors is important for a diverse array of investigations, including the study of vent sites, and for locating the source of chemical signals originating from the seafloor. The hypoxic basin example here permits better discrimination between general climate/ circulation controls on hypoxia and more specific point-source-driven processes.
\end{abstract}

\section{Introduction}

Declining oceanic oxygen associated with climate change and human development (Nakanowatari et al. 2007; Stramma et al. 2008; Helm et al. 2011) and concerns over the impacts of growing low-oxygen regions of the ocean on ecosystem functioning and fisheries (Diaz and Rosenberg 2008; Ekau et al. 2010; J. Zhang et al. 2010) has led to the need for better definitions of limiting values for key species and ecosystems (Hofmann et al. 2011; Seibel 2011). In the past, relatively crude definitions have been used, such as a threshold in $\left[\mathrm{O}_{2}\right]$, with no specific temperature $T$ dependence for comparison

Corresponding author address: Peter G. Brewer, Monterey Bay Aquarium Research Institute, 7700 Sandholdt Road, Moss Landing, CA 95039-9644.

E-mail: brpe@mbari.org between regions differing greatly in latitude. Furthermore, traditional hydrographic surveys with discrete and coarsely spaced sampling are not well matched to modern high-resolution seafloor topographic detail that defines critical benthic habitats and the associated topographically forced flow.

High-resolution surveys of multiple key hypoxiadefining parameters are potentially capable of resolving questions such as the distinction between generalized warming and decreasing $\left[\mathrm{O}_{2}\right]$ that are driven by global processes, and evidence for point-source-driven change and impacts from riverine, urban, or agricultural releases that may be subject to local policy control. The detailed mapping of critical oxygen boundaries, the variation with topography, and the use of these data to define the oxygen resource available to marine life with varying oxygen demands as a function of depth and $T$ may be used to efficiently monitor rapidly expanding hypoxic 
regions that are now evident in coastal regions around the world.

While near-bottom, terrain-following autonomous underwater vehicle (AUV) missions are now routinely used for bathymetric mapping (e.g., Caress et al. 2008; Yoerger et al. 2007; Caress et al. 2012), general hydrographical and current measurements (Stansfield et al. 2001), and tracking of oil-spill-related hydrocarbons (e.g., Camilli et al. 2010), AUV missions to simultaneously monitor various hypoxia-related parameters are not yet an established tool. In this paper we seek to advance this field by reporting on the execution of and results from a high-resolution bottom-following AUV survey of critical chemical properties $\left[\mathrm{pO}_{2}\right.$ (as calculated from $\left[\mathrm{O}_{2}\right]$ ), as well as $\left[\mathrm{NO}_{3}\right], T$, and $\left.S\right]$ in the Santa Monica Basin, offshore Southern California. The obtained chemical data are then mapped onto the topography with sufficient resolution to define the ocean chemical conditions supporting or limiting benthic and pelagic populations.

In planning and conducting this survey, we paid particular attention to reducing cost. We used the 26-m Research Vessel (R/V) Zephyr with a scientific party of four to execute the 3-day survey. The trade-off is that on vessels of this size, there is no room for personnel for conventional hydrocasts and chemical laboratory systems.

\section{Santa Monica Basin}

The Santa Monica Basin, located in the Southern California Bight (McClatchie et al. 2010), has long been known as an oxygen-deficient environment (Emery 1960; Bograd et al. 2002; Masiello and Druffel 2003). It receives water from the California Current (Emery 1960; Hickey 1991, 1992), which is well known for hypoxic conditions (Mearns and Smith 1976; Bograd et al. 2008; McClatchie et al. 2009; Connolly et al. 2010); however, the deep waters of the basin are most likely fed by the poleward undercurrent flowing from the south. Below the sill depth at $740 \mathrm{~m}$ (Emery 1960), dissolved oxygen levels are consistently below the traditionally accepted (Shaffer et al. 2009) suboxic level of $10 \mu \mathrm{mol} \mathrm{kg}^{-1}$ (Bograd et al. 2002) and occasionally even fall below $5 \mu \mathrm{mol} \mathrm{kg}{ }^{-1}$ (Bograd et al. 2002), which is sometimes used as a tighter threshold for suboxia (Rue et al. 1997). Although the basin is periodically flushed (Emery 1960; Hickey 1991; Bograd et al. 2002), the waters immediately above sill depth are also low in oxygen and the basin deep waters are essentially permanently suboxic with a marked nitrate deficit. Intense reducing activity in the sulfide-rich sediments coupled with locally intense methane leakage has been shown (Paull et al. 2008), and this quickly reduces any oxygen introduced during periodic water flushing events (Bograd et al. 2002).
The overlying waters below a depth of about $100 \mathrm{~m}$ have dissolved oxygen levels below $61 \mu \mathrm{mol} \mathrm{kg}{ }^{-1}\left(\mathrm{pO}_{2} \approx\right.$ 60 matm at $25^{\circ} \mathrm{C}$; see Hofmann et al. 2011) and thus some $640 \mathrm{~m}$ of the water column is poised below the widely accepted oxygenation level defining coastal hypoxia (Gooday et al. 2009; Middelburg and Levin 2009; Levin et al. 2009; J. Zhang et al. 2010). These midwaters thus fall well within the range defined as a "dead zone" in other nearshore locations, such as the Mississippi Delta in the Gulf of Mexico (Turner et al. 2008). The waters here do contain aerobic species highly adapted to low-oxygen conditions. However, even these species reach their limit very close to oxygen conditions established at the sill depth of the basin [Childress and Seibel 1998, and Monterey Bay Aquarium Research Institute (MBARI) remotely operated vehicle (ROV) observations].

The decomposition of anthropogenic organic waste discharged into the ocean can cause or exacerbate hypoxic conditions. Horizontal gradients in oxygenation of the flat parts of the basin bottom (i.e., not related to water depth) might indicate point-source-driven oxygen drawdown processes possibly connected to anthropogenic waste disposal. Such horizontal gradients could be detected by a high-resolution, topography-following AUV survey. The generally low-oxygen content, the possible existence of horizontal oxygen gradients, and a topography characterized by the presence of two significant mounds within the near-shelf part of the basin (Paull et al. 2008) together with a size suitable for the range of autonomous underwater vehicles available today makes the Santa Monica Basin an ideal test bed for an AUV survey method capable of efficiently resolving the distribution of hypoxia-defining oceanographic parameters.

\section{Materials and methods}

\section{a. AUV operations}

The survey described here was conducted with a variation of the MBARI AUV "Dorado" (Bellingham et al. 2000; Sibenac et al. 2002) launched from the MBARI R/V Zephyr on a week-long cruise in early June 2011. Depending on configuration (for other configurations, see Johnson and Needoba 2008; Ryan et al. 2010, 2011), the Dorado can carry a variety of chemical sensors. The main chemical sensor for this mission was a pair of Sea-Bird SBE43 oxygen sensors aided by a pair of Sea-Bird Electronics (SBE) conductivity, $T$, and pressure (CTD) sensor arrays (SBE3F and SBE4) mounted in a continuously pumped sample stream. Calibration of the oxygen sensors is regularly ensured by the MBARI AUV team according to standard Sea-Bird Electronics Inc. recommended 

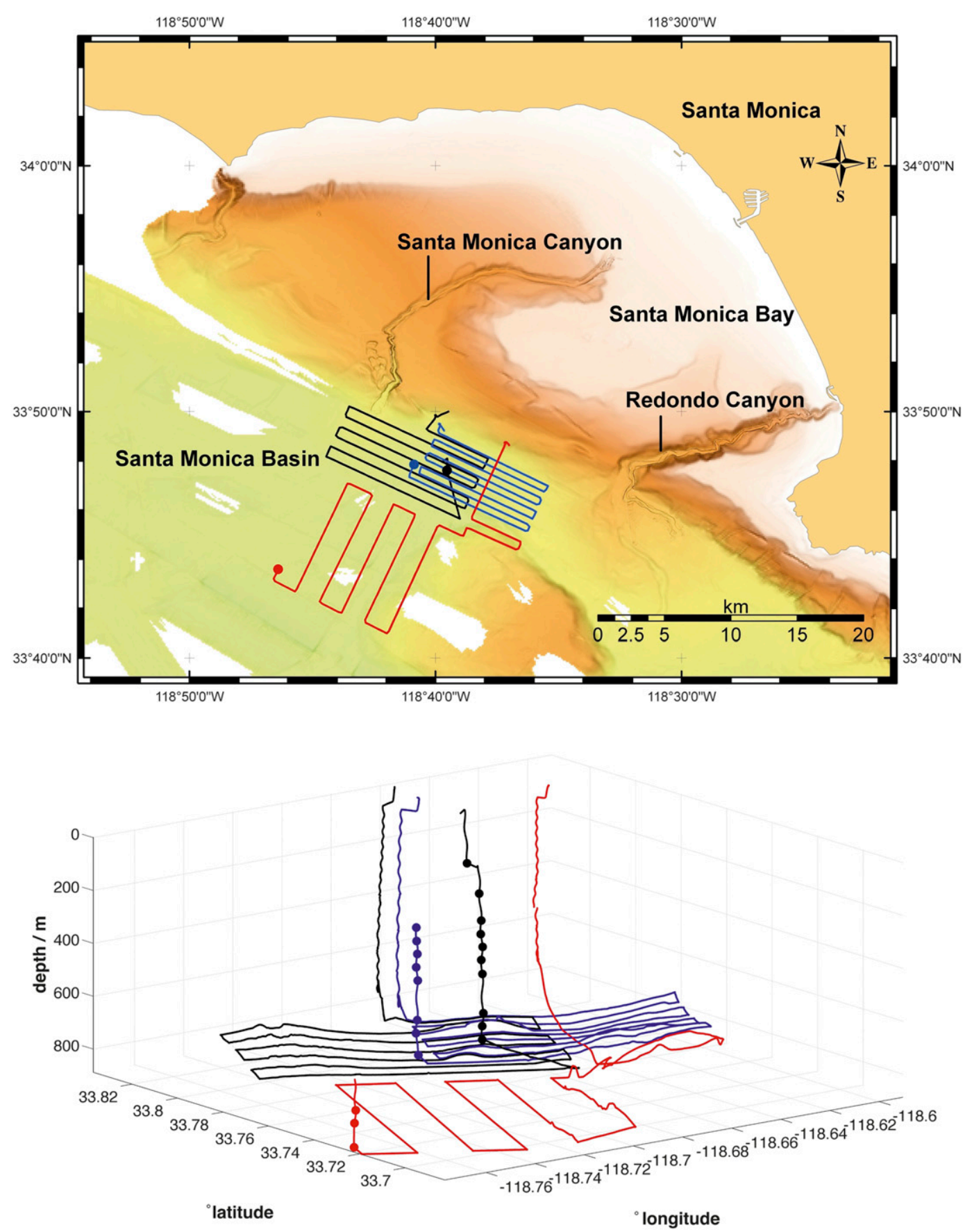

FIG. 1. Location of the three AUV dives. (top) Overview map of Santa Monica Bay and the mapped part of Santa Monica Basin showing dive 1 ( black), dive 2 (blue), and dive 3 (red). The colored dots indicate the first (deepest) of the locations of the sampling with the AUV-mounted Gulper water sampling system. (bottom) 3D representation of the three dives [color code as in (top)] showing the spiraling of the vehicle through the water column to reach the bottom. Shorter vertical lines for dives 2 and 3 indicate that data collection and Gulper sampling stopped during the vehicle ascent because of a lack of battery power. The colored dots indicate the locations where the Gulper water samples were taken: 10 in dive 1,8 in dive 2 , and 3 in dive 3. 


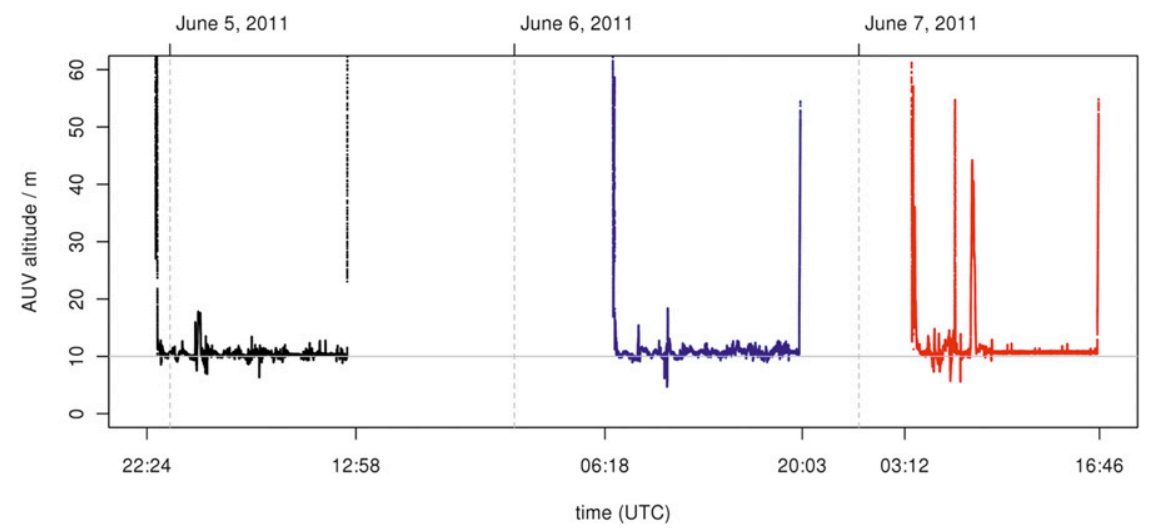

FIG. 2. AUV altitude (distance to the seafloor) for all three dives. The vehicle was programmed to fly a constant altitude of $10 \mathrm{~m}$, as indicated by the horizontal gray line. Because of complex seafloor topography and limited pitch angle, it is not always possible to maintain this constant altitude. Vertical dashed lines indicate UTC date changes, and UTC times on the abscissa indicate the start and end of each dive.

procedures. The vehicle also carried the MBARIdeveloped in situ ultraviolet spectrophotometer (ISUS; Johnson and Coletti 2002), which measures nitrate and bisulfide concentrations. A Hobi Laboratories HydroScat-2 (HS2) backscattering sensor, a fluorometer measuring turbidity at 420 and $700 \mathrm{~nm}(\mathrm{~nm})$ and chlorophyll- $a$ fluorescence, and a Wet Laboratories Environmental Characterization Optics (ECO) fluorescence (fl) colored dissolved organic matter (CDOM) sensor were also operated on the vehicle.

The AUV was also fitted with the MBARI "Gulper" water sampling system (Bird et al. 2007; Ryan et al. 2010), designed to rapidly acquire multiple large-volume water samples. The Gulper sampling system consists of 10 spring-loaded and electronically activated syringe-like water samplers with a volume of $2 \mathrm{~L}$ each, mounted in the midbody of the vehicle. For this mission, the Gulper system was used to conduct analogs to traditional Niskin bottle hydrocasts by triggering the sampler syringes at given depths during the vehicle ascent after each dive.

It was not possible within the confines of the mission and ship space to carry out traditional CTD hydrocasts and conventional Winkler titrations. ${ }^{1}$ Oxygen calibration and sensor stability were examined from comparison of the up- and down-water column transit. Each

\footnotetext{
${ }^{1}$ Also, in practice, for such low- $\mathrm{O}_{2}$ environments there is significant doubt as to the accuracy of Winkler titrations (Thamdrup et al. 2012). Although modified titration techniques for low- $\mathrm{O}_{2}$ systems have been devised, the problems of significant $\mathrm{O}_{2}$ contamination from leakage from polymers have only recently been recognized. For example, the Teflon-coated stir bars almost universally used during Winkler titrations are a significant source of $\mathrm{O}_{2}$ contamination.
}

AUV deployment was long enough that sufficient immersion time in very low- $\mathrm{O}_{2}$ waters was achieved so that any $\mathrm{O}_{2}$ bleed from the polymer structures surrounding the Sea-Bird SBE43 electrode was greatly diminished.

For the mission described here, the Dorado AUV was fitted with the MBARI mapping vehicle tail cone (Kirkwood 2007; Paull et al. 2008; Maier et al. 2011) that carries an inertial navigation system (INS) aided by velocity-over-ground observations from a Doppler velocity $\log$ (DVL), capable of achieving $0.05 \%$ of distance traveled navigational accuracy. The system was initialized remotely over an acoustic modem connection once bottom lock was established. Bottom lock was maintained throughout the rest of the dives. In the used configuration, the AUV is $5.33 \mathrm{~m}$ long and $54 \mathrm{~cm}$ in diameter, and can fly missions of $\approx 70-\mathrm{km}$ track length at $\approx 2.8 \mathrm{kt}(1 \mathrm{kt}=$ $\left.5.1 \mathrm{~km} \mathrm{~h}^{-1}\right)$.

Three separate dives were conducted on 5-7 June 2011 in the Santa Monica Basin just off the slope of Santa Monica Bay (see Fig. 1): dive 1: $\approx 73-\mathrm{km}$ track length at $\approx 2.7 \mathrm{kt}\left(5 \mathrm{~km} \mathrm{~h}^{-1}\right), \approx 14.5$-h duration; dive 2 : $\approx 70-\mathrm{km}$ track length at $\approx 2.8 \mathrm{kt}\left(5.1 \mathrm{~km} \mathrm{~h}^{-1}\right), \approx 13.7-\mathrm{h}$ duration; and dive $3: \approx 71-\mathrm{km}$ track length at $\approx 2.9 \mathrm{kt}$ $\left(5.3 \mathrm{~km} \mathrm{~h}^{-1}\right), \approx 13.5$-h duration. During all dives, an AUV altitude (distance to bottom) of $\approx 10 \mathrm{~m}$ was maintained (see Fig. 2).

\section{b. Laboratory sample processing}

Immediately after recovering the vehicle, nutrient samples were drawn from the Gulper water sampling bottles into seasoned polyethylene scintillation vials and frozen aboard the R/V Zephyr for later processing with an AlpChem autoanalyzer in the MBARI laboratory (Sakamoto et al. 1990). The samples were analyzed for 

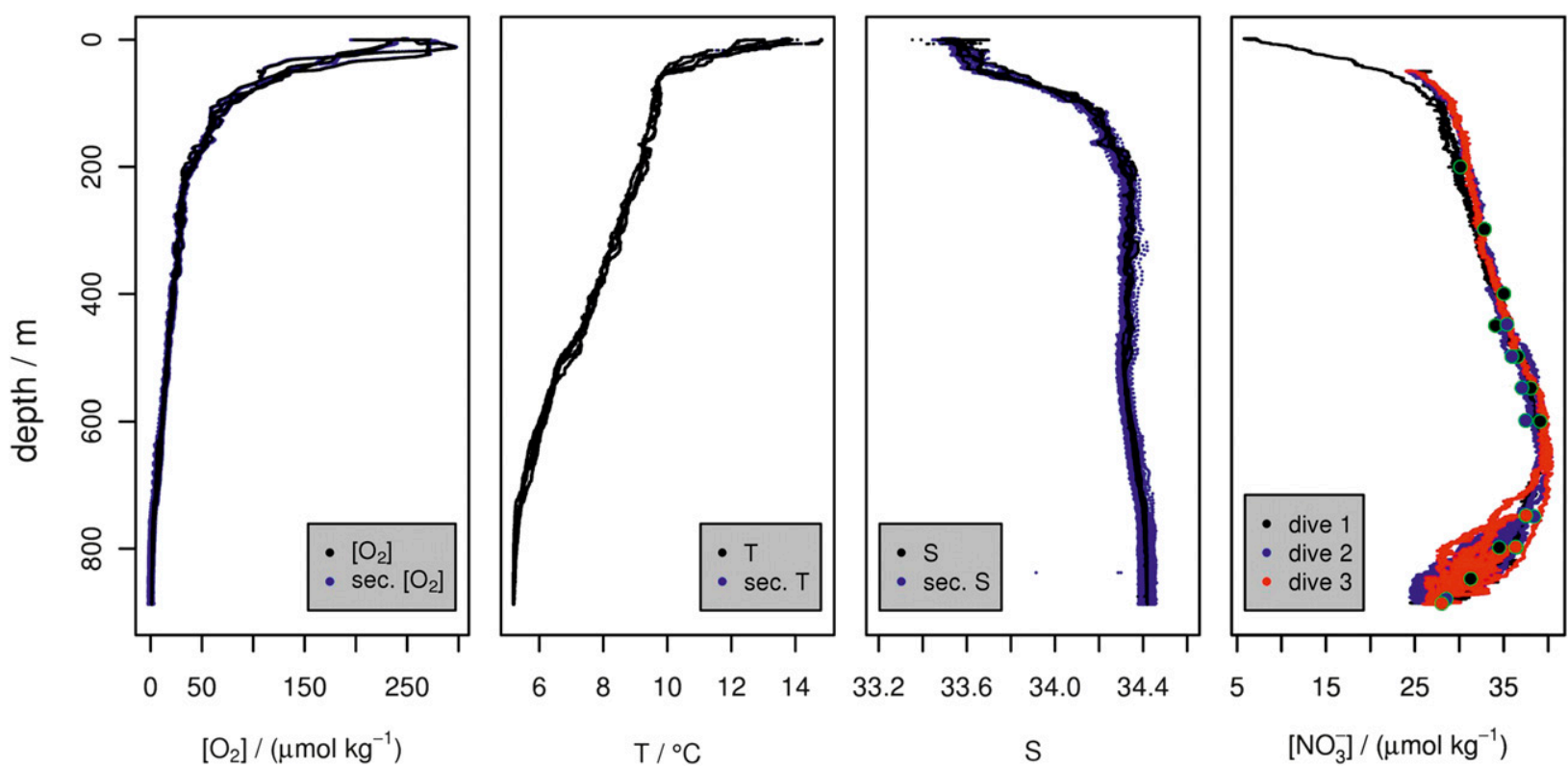

FIG. 3. Scatterplots of $\left[\mathrm{O}_{2}\right], T, S$, and $\left[\mathrm{NO}_{3}^{-}\right]$data obtained from the AUV instrumentation (details in the text), both with primary and secondary (sec.) sensors. For comparison, green circled larger dots in the $\left[\mathrm{NO}_{3}^{-}\right]$profile indicate data obtained from laboratory-analyzed samples taken with the AUV-mounted Gulper water sampling system (see also Fig. 5).

$\mathrm{NO}_{3}^{-}, \mathrm{NO}_{2}^{-}, \mathrm{PO}_{4}^{3-}$, and $\mathrm{Si}(\mathrm{OH})_{4}$ concentrations. All nutrient concentration data have been baseline corrected by linear interpolation using low-nutrient seawater reference samples that have been analyzed while interspersed with the samples obtained from the AUV survey.

\section{c. Data processing}

Raw vehicle navigation and sensor log files were processed using an extensive set of MBARI-maintained MATLAB scripts (http://www.mbari.org/muse/platforms/ auvsdp.html) to apply sensor-specific conversion and correction factors and to take into account sensor lag times, pumping lag times corresponding to the location of the respective sensor in the pumping stream within the vehicle, and the vehicle velocity. Using vehicle navigation data, all sensor data were then correctly located in time and space for the final data products. This means that each data value is associated with the in situ location of the parcel of water that was sampled. As a result, no sensor lag times or other kinds of spatial or temporal shifts need to be considered when interpreting results shown in this paper. Full-resolution data products contained about 200000 data points per dive for oxygen, CTD, and HS2 data (sampled with a frequency of $\approx 4 \mathrm{~Hz}$ ), and 50000 data points for ISUS data (sampled with a frequency of $\approx 1 \mathrm{~Hz}$ ). Data from all sensors were interpolated to one common series of time stamps.

The $\left[\mathrm{NO}_{3}^{-}\right]$values were first calculated from ISUS sensor data using the algorithm described in Johnson and Coletti (2002). In a subsequent step, poor-quality data in the warm-up phase of the instrument at the start of each dive were removed and the remaining data have been reprocessed according to Sakamoto et al. (2009) to correct for in situ salinity $S$ and $T$ using averages of data from the primary and secondary CTD sensors. Furthermore, as is standard procedure for many oceanographic expeditions and sensor deployments, a postdive processing of $\left[\mathrm{NO}_{3}^{-}\right]$data has been performed, as detailed in appendix A.

For 3D representations of key measured parameters, especially $\mathrm{pO}_{2},\left[\mathrm{O}_{2}\right],\left[\mathrm{NO}_{3}^{-}\right], T$, and $S$, the data for all three dives have been merged into one dataset containing about 600000 data points. Subsequently, only data with an AUV altitude (distance to the bottom) of below $20 \mathrm{~m}$ were considered, since our objective was to characterize low-oxygen bottom waters in the Santa Monica Basin.

Values for chlorophyll- $a$ fluorescence (fl676), optical backscatter (bbp470 and bbp676), and colored dissolved organic matter (CDOM-ECOfl) are reported here in the native engineering units of the sensors. For chlorophyll fluorescence, an approximate conversion from engineering units to chlorophyll concentrations in micrograms per liter was determined to be $(0.0007)^{-1}$ for another mission (Johnson and Needoba 2008).

Hydrostatic-pressure-corrected (according to Enns et al. 1965) $\mathrm{pO}_{2}$ values have been calculated from AUV $\left[\mathrm{O}_{2}\right], S, T$, depth, and position data for all three dives 
(see Hofmann et al. 2011). The depth at which $\mathrm{pO}_{2}$ values cross hypoxia thresholds A (106 matm) to C (22 matm) as defined in Hofmann et al. (2011) have been determined based on values averaged between the three dives. Furthermore, we calculated the distance in terms of potential density $\left(\Delta \sigma_{\theta}\right.$; see Hofmann et al. 2011) of waters of the respective hypoxia categories from the 200- $\mathrm{m}$ isobath, indicative for the global average depth of the start of the continental shelf where upwellinginduced coastal hypoxia might occur.

Following Hofmann et al. (2012), a set of quantities was calculated from $T, S$, hydrostatic pressure $P$, and $\left[\mathrm{O}_{2}\right]$, integrating $\left[\mathrm{O}_{2}\right]$ availability and diffusive limitation of $\mathrm{O}_{2}$ uptake, that each characterize particular aspects of hospitality of a given oceanic environment for aerobic life. Here $C_{f}$ defines the minimum $\left[\mathrm{O}_{2}\right]$ required at in situ $T, P$, and diffusivity to support a given laboratorydetermined (at $1 \mathrm{~atm}$ ) uptake rate. The quantity $E_{\max }$ defines the generic maximal $\mathrm{O}_{2}$ supply rate to an organism per square centimeter of respiratory surface area, and this allows for direct comparison of different ocean regions. The quantity $\Delta u_{100}$ represents the change in local bulk fluid flow rate required to offset a given ocean warming and deoxygenation scenario.

\section{Results}

\section{a. Water column observations}

The $\left[\mathrm{O}_{2}\right], T$, and $S$ data show a good consistency between primary and secondary CTD and [O2] sensors (Fig. 3, left three panels); only the secondary $S$ sensor shows somewhat more data spread than the primary sensor (Fig. 3, middle-right panel). After postprocessing and linear shift correction, the nitrate data for all three dives are consistent between dives and with laboratoryanalyzed discrete samples (Fig. 3, right panel).

The $\left[\mathrm{O}_{2}\right]$ profiles (Fig. 3, leftmost panel) are very consistent between the three dives and show a quasiexponential decline from supersaturated values at the surface (Garcia and Gordon 1992: $\mathrm{O}_{2}$ saturation concentration for $S=33.5$ and $T=15^{\circ} \mathrm{C}$ is $\approx 250 \mu \mathrm{mol} \mathrm{kg}^{-1}$ ) to values of about $50 \mu \mathrm{mol} \mathrm{kg}{ }^{-1}$ at a depth of $200 \mathrm{~m}$. From $200 \mathrm{~m}$ on, the $\left[\mathrm{O}_{2}\right]$ declines in an approximately linear fashion all the way to the bottom at $\approx 900$-m depth. The decline slightly levels off at around $750 \mathrm{~m}$. The $\left[\mathrm{O}_{2}\right]$ is less than $10 \mu \mathrm{mol} \mathrm{kg}{ }^{-1}$ below about $650 \mathrm{~m}$ and the bottom $\left[\mathrm{O}_{2}\right]$ values are as low as $0.5 \mu \mathrm{mol} \mathrm{kg}{ }^{-1}$. The temperature (Fig. 3, middle-left panel) steeply decreases from about $15^{\circ} \mathrm{C}$ at the surface to about $10^{\circ} \mathrm{C}$ at about $50-\mathrm{m}$ depth. At this depth, the slope of the decrease sharply changes, resulting in the onset of a more gradual quasi-linear decrease, until a $T$ of about $5.5^{\circ} \mathrm{C}$ is reached at a depth of

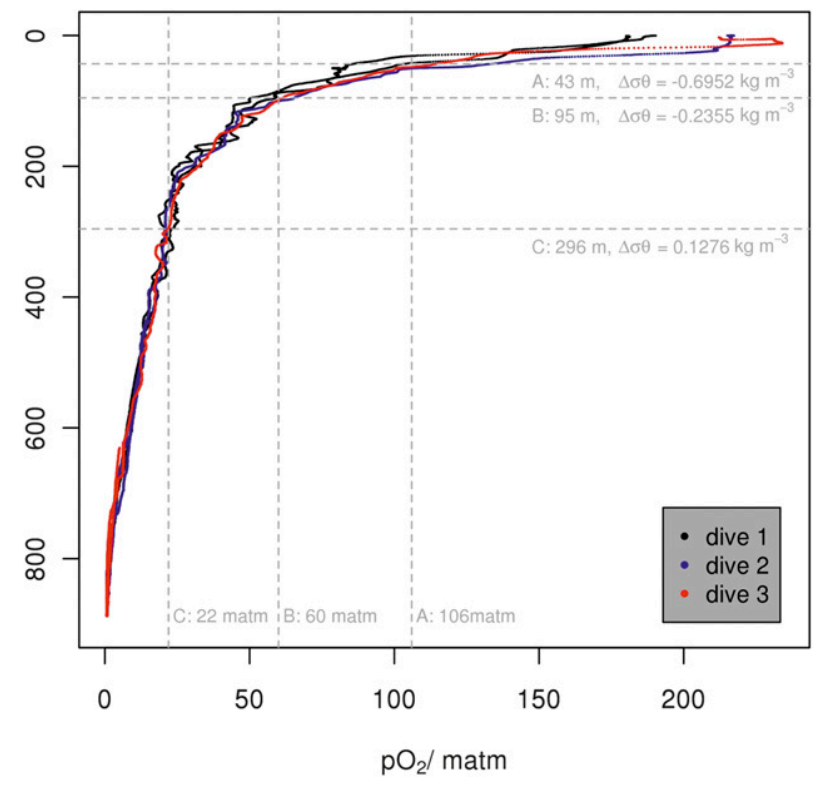

FIG. 4. Scatterplot of hydrostatic-pressure-corrected (Enns et al. 1965) $\mathrm{pO}_{2}$ calculated from AUV $\left[\mathrm{O}_{2}\right], S, T$, depth, and position data for all three dives. Vertical dashed lines indicate hypoxia thresholds for categories A-C as defined in Hofmann et al. (2011). Horizontal lines indicate the depth values at which, averaged over the three dives, the respective hypoxia category is attained first, i.e., below which $\mathrm{pO}_{2}$ values are below the respective threshold. The distance in terms of potential density $\left(\Delta \sigma_{\theta}\right.$; see Hofmann et al. 2011) of waters of the respective hypoxia categories from the 200-m isobath, indicative of the global average depth of the start of the continental shelf, is also given.

about $750 \mathrm{~m}$. Then $T$ continues to decrease with a very slight gradient with depth but remains above $5^{\circ} \mathrm{C}$ down to the bottom. Salinity values (Fig. 3, middle-right panel) only slightly increase from values around 33.5 in the upper $50 \mathrm{~m}$ and exhibit a higher degree of variability than below $50 \mathrm{~m}$. Between 50 and $\approx 150 \mathrm{~m}, S$ steeply increases to values of $\approx 34.2$. This increase levels off, and $S$ remains virtually constant around 34.35 down to about $550 \mathrm{~m}$. Then another slight increase can be observed until $S$ remains again virtually constant at 34.4 between $\approx 750 \mathrm{~m}$ and the bottom. The value of $\left[\mathrm{NO}_{3}^{-}\right]$(Fig. 3, rightmost panel) steeply increases in the upper $100 \mathrm{~m}$ from $\approx 5 \mu \mathrm{mol} \mathrm{kg}^{-1}$ at the surface to about $25 \mu \mathrm{mol} \mathrm{kg}^{-1}$. At this depth, the slope of the increase sharply changes and a less strong but still linear increase commences until values of $\approx 40 \mu \mathrm{mol} \mathrm{kg}^{-1}$ are reached at a depth of about $650 \mathrm{~m}$. There, $\left[\mathrm{NO}_{3}^{-}\right]$values decline sharply again, reaching values of around $25 \mu \mathrm{mol} \mathrm{kg}^{-1}$ at the bottom. After the linear shift correction, ISUS $\left[\mathrm{NO}_{3}^{-}\right]$values are, on the scale and level of detail given in Fig. 3 (i.e., $\approx \pm 1 \mu \mathrm{mol} \mathrm{kg}^{-1}$ ), fairly consistent between all three dives, even though the poor-quality offset of $-0.45 \mu \mathrm{mol} \mathrm{kg}{ }^{-1}$ has not been applied to dive 3. Also, on the same scale 

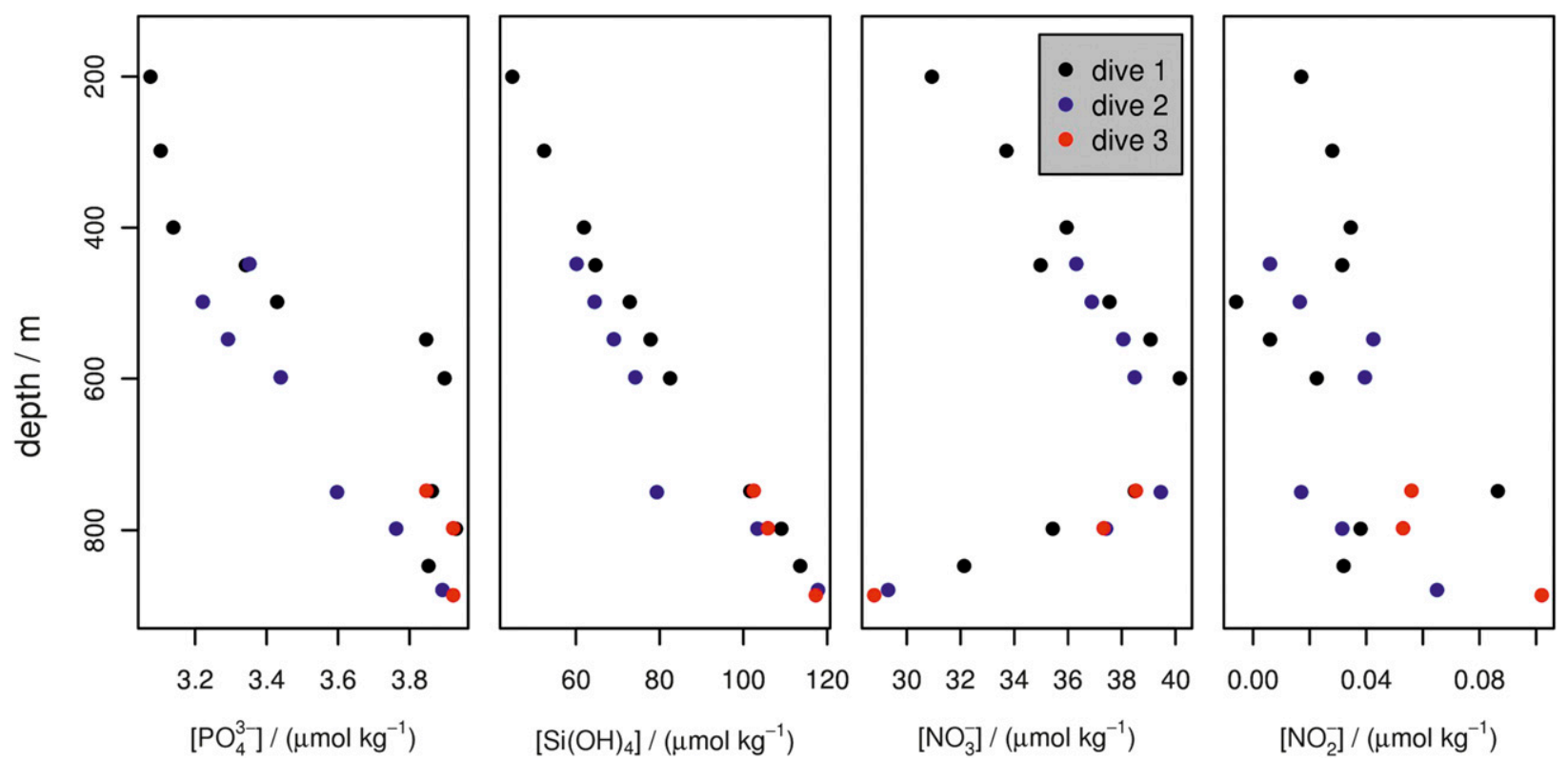

FIG. 5. Depth profiles of laboratory-analyzed nutrient samples taken with the AUV-mounted Gulper water sampling system. Locations of sampling are indicated in Fig. 1.

and level of detail, $\left[\mathrm{NO}_{3}^{-}\right]$values are consistent with data from laboratory-analyzed Gulper samples throughout the whole water column.

The $\mathrm{pO}_{2}$ values steeply and quasi-linearly decline in the upper $100 \mathrm{~m}$ (Fig. 4), reaching the hypoxia category A threshold value (Hofmann et al. 2011) of 106 matm at a depth of $43 \mathrm{~m}$ (averaged over all three dives) and the hypoxia category $\mathrm{B}$ threshold of 60 matm at $\approx 95 \mathrm{~m}$. From about $100 \mathrm{~m}$ on, the $\mathrm{pO}_{2}$ decline gradually levels off, reaches the hypoxia category $\mathrm{C}$ threshold of 22 matm at $\approx 296 \mathrm{~m}$, and settles into an again quasi-linear decline with a much less steep slope from $\approx 220 \mathrm{~m}$ all the way down to $750 \mathrm{~m}$, where values of around $0.5 \mathrm{matm}$ are attained. Hofmann et al. (2011) defined a proxy for the potential energy that has to be overcome to transport a parcel of low-oxygen water onto the continental shelf, where upwelling-induced coastal hypoxia can be caused: the potential density distance from the $200-\mathrm{m}$ isobath, $\Delta \sigma_{\theta}$. Here, $\Delta \sigma_{\theta}$ is $\approx 0.1276 \mathrm{~kg} \mathrm{~m}^{-3}$ for hypoxia category $\mathrm{C}$ waters $\left(\mathrm{pO}_{2} \leq 22\right.$ matm), while hypoxia categories $\mathrm{B}$ and $\mathrm{A}$ waters are already within shelf depths, indicated by negative $\Delta \sigma_{\theta}$ values.

The AUV-mounted Gulper system was used to take water samples between the bottom and 200-m depth (Fig. 5 and Table 1). The phosphate concentration $\left[\mathrm{PO}_{4}^{3-}\right]$ (Fig. 5, leftmost panel) increases from $\approx 3 \mu \mathrm{mol} \mathrm{kg}^{-1}$ at $200 \mathrm{~m}$ to $\approx 3.9 \mu \mathrm{mol} \mathrm{kg}^{-1}$ at the bottom. The increase can in general be characterized as linear with depth, where dive 1 shows a slightly steeper slope in the upper $400 \mathrm{~m}$ than dive 2 , which shows between $400 \mathrm{~m}$ and the bottom. While data for dive 2 appear to increase linearly below $400 \mathrm{~m}$ also, dive 1 exhibits a slight positive anomaly from linear increase at depths around $600 \mathrm{~m}$. Gulper sample data are scarce for dive 3 since the sequence of Gulper samples was not completed because of a lack of AUV battery power, but the three deepest data points of dive 3 are very consistent with dive 1 . Silicate concentration $\left[\mathrm{Si}(\mathrm{OH})_{4}\right]$ (Fig. 5, middle-left panel) linearly increases in all three dives from about $40 \mu \mathrm{mol} \mathrm{kg}^{-1}$ at 200-m depth to about $120 \mu \mathrm{mol} \mathrm{kg}^{-1}$ on the bottom at $\approx 900 \mathrm{~m}$. All three dives are relatively consistent with dive 2 showing slightly lower values than dives 1 and 3 . Although there are only three data points for dive 3 , the correlation of laboratory-obtained $\left[\mathrm{NO}_{3}^{-}\right]$values with depth (Fig. 5, middle-right panel) seems to be very consistent between all three dives and $\left[\mathrm{NO}_{3}^{-}\right]$values increase quasi-linearly from $\approx 31 \mu \mathrm{mol} \mathrm{kg}{ }^{-1}$ at $200 \mathrm{~m}$ to $\approx 40 \mu \mathrm{mol} \mathrm{kg}^{-1}$ at $600 \mathrm{~m}$ and decline again from there to about $28 \mu \mathrm{mol} \mathrm{kg}^{-1}$ at the bottom. Nitrite concentrations $\left[\mathrm{NO}_{2}^{-}\right]$(Fig. 5, rightmost panel) are generally very low and close to the detection limit. While a clear peak cannot be identified, an increasing trend with depth seems apparent.

As expected, chlorophyll- $a$ fluorescence (Fig. 6, leftmost panel) exhibits a peak in the upper $50 \mathrm{~m}$ and then remains virtually zero all the way to the bottom, with values being very noisy below $800 \mathrm{~m}$. Optical backscatter values (Fig. 6, middle-left and middle-right panels) show peaks in the euphotic zone consistent with the chlorophyll- $a$ fluorescence peak, indicating algal biomass. Below $50 \mathrm{~m}$, 


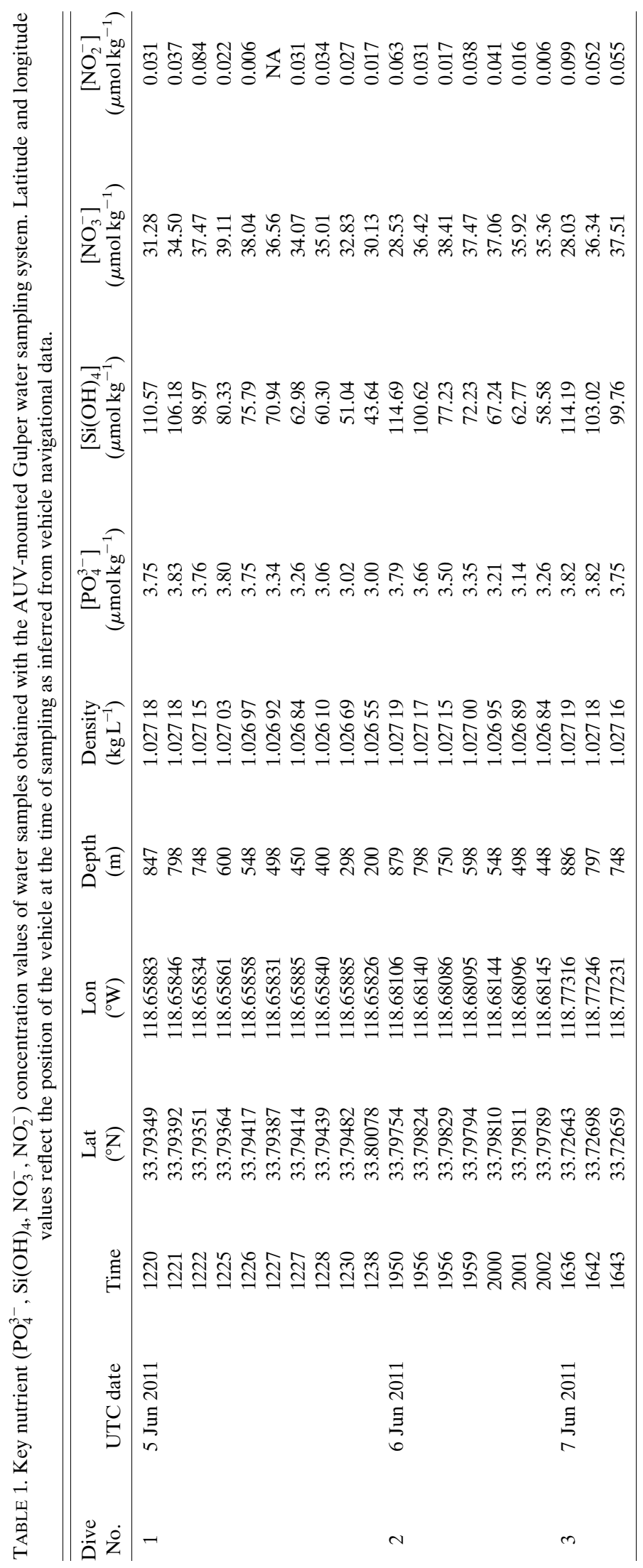




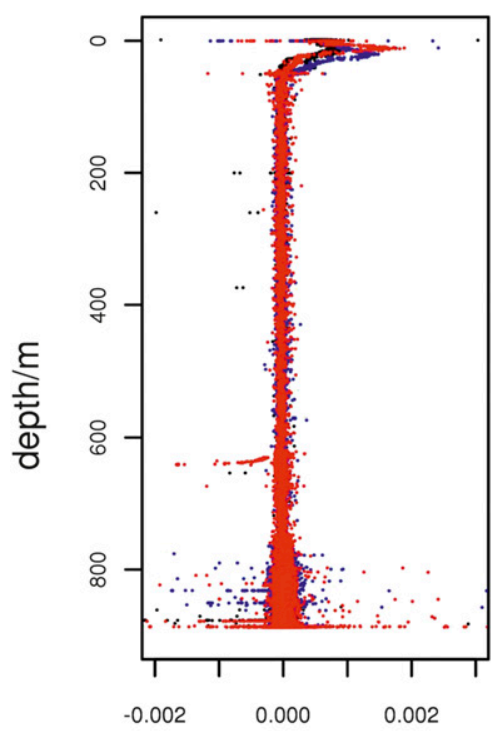

fl676

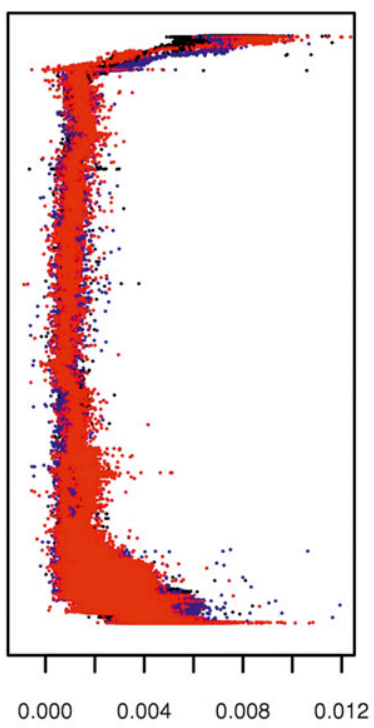

bbp470

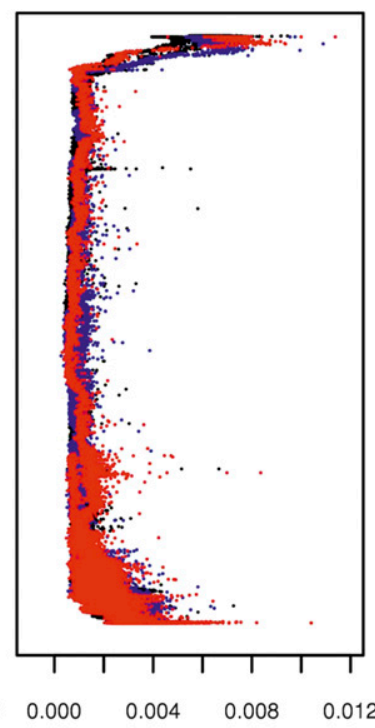

bbp676

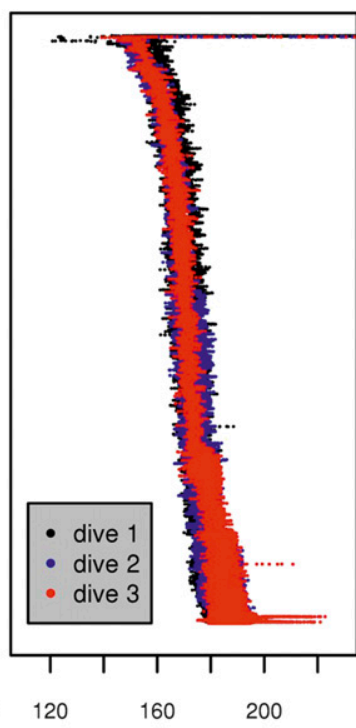

$\operatorname{CDOM}(\mathrm{ECOfl})$

FIG. 6. Scatterplots of chlorophyll fluorescence (fl767), optical backscatter at $470 \mathrm{~nm}$ (bbp470) and $676 \mathrm{~nm}$ (bbp676) wavelength, as well as a proxy for CDOM. All data are obtained from the AUV instrumentation (details in the text) and are in relative engineering units.

backscatter at both 470 and $676 \mathrm{~nm}$ remains virtually constant at low values until about $750 \mathrm{~m}$, where a marked increase can be observed again, indicating water of higher turbidity in the bottom $150 \mathrm{~m}$ of the basin, with backscatter reaching values almost as high as in the euphotic zone. At about $650 \mathrm{~m}$, a slight positive anomaly can be observed for both wavelengths. CDOM (Fig. 6, rightmost panel) linearly increases from the surface to the bottom throughout the whole water column. The upper $\approx 100 \mathrm{~m}$ show a steeper slope than the waters from $100 \mathrm{~m}$ down to the bottom.

\section{b. Water-column-derived quantities}

Hofmann et al. (2012) treat hypoxia as a gas exchange problem for animals analogous to familiar gas exchange processes at the sea surface. They define three novel ocean quantities by mechanistically combining several well-known nonlinear oceanic properties in ways that allow for mapping, visualization, and thus comprehension of their combined effect on the diffusion-limited oxygen supply of the ocean that any animal demand has to face. Here we apply these properties to better illuminate the conditions of $\mathrm{O}_{2}$ stress that exist and how these will change with ocean warming.

The term $C_{f}$, the minimal free stream $\left[\mathrm{O}_{2}\right]$ that sustains a given oxygen uptake rate, expresses the purely physical influences of $T, S$, hydrostatic pressure, and current flow velocity on the gas transport across the diffusive boundary layer (DBL) over gas exchange surfaces throughout the ocean. The $E_{\max }$, the maximal oxygen uptake rate per area of gas exchange surface that a particular oceanic environment can support, additionally incorporates the ambient oxygen content to express in one number the oceanic environment's capability to support aerobic life. Finally, $\Delta u_{100}$, the flow velocity offset needed to compensate for given ocean warming and deoxygenation (here, the decrease in $\left[\mathrm{O}_{2}\right]$ associated with warming due to the decrease in oxygen solubility) is a quantity that incorporates yet another dimension: an estimate for the (metabolic) costs of future changes of $T$ and $\left[\mathrm{O}_{2}\right]$, and therefore this represents the vulnerability of a given system to global change.

Based on the measured data and assuming a generic fluid flow velocity of $2 \mathrm{~cm} \mathrm{~s}^{-1}$, comparable to observed ambient current velocities in the Santa Monica Basin (Hickey 1991), we can calculate the quantities that express environmentally imposed diffusive oxygen uptake limitations for aerobic marine life as defined in Hofmann et al. (2012) (Fig. 7). For a given uptake rate, minimally required oxygen concentration $C_{f}$ is dominated by $T$ in the upper $750 \mathrm{~m}$; the $C_{f}$ curve (Fig. 7, left panel) exhibits the inverse shape of the $T$ profile, as decreasing $T$ increases diffusive limitation. Below $750 \mathrm{~m}$ the dominance of the effect of hydrostatic pressure at greater depths (increasing hydrostatic pressure decreases diffusive limitation as it increases the driving $\mathrm{pO}_{2}$ ) starts to become apparent as $C_{f}$ starts to decline again (i.e., a lower concentration is needed to sustain a given oxygen uptake rate). The term $E_{\max }$ (Fig. 7, middle panel) is dominated by $\left[\mathrm{O}_{2}\right]$ and the profiles therefore look similar to the $\left[\mathrm{O}_{2}\right]$ 

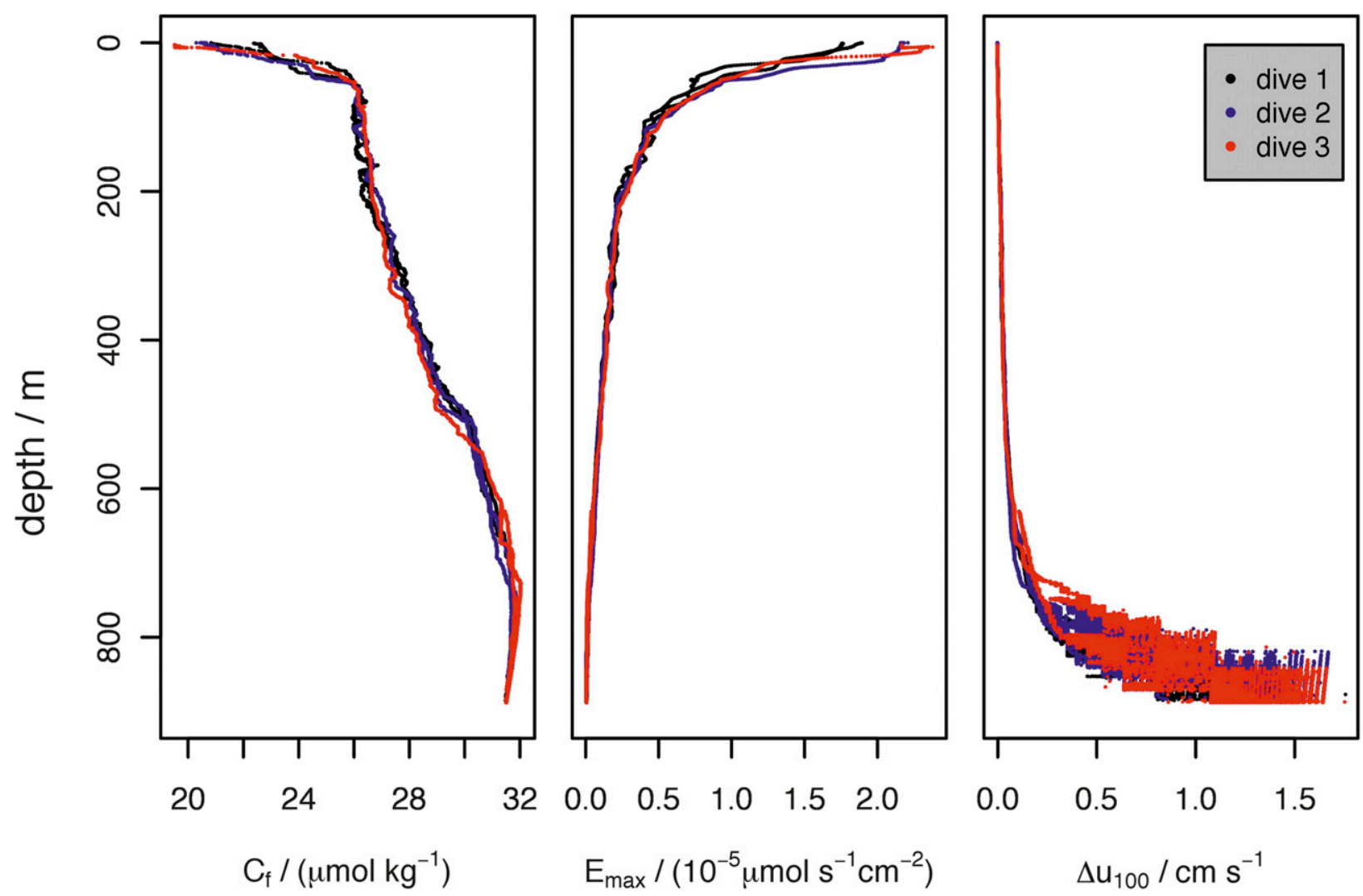

FIG. 7. Quantities to describe hospitability for aerobic organisms according to Hofmann et al. (2012): $C_{f}$ is the $\left[\mathrm{O}_{2}\right]$ value the free stream water must minimally have to sustain a given oxygen uptake rate $E$ (we use a generic example value of $E=20 \times 10^{-7} \mu \mathrm{mol} \mathrm{s}^{-1} \mathrm{~cm}^{-2}$ here). It represents the influence of $T, S$, and pressure on oxygen uptake rates. The $E_{\max }$ represents the maximal oxygen uptake rate the given environment is capable of sustaining. It combines the effects of $T, S$, and pressure with ambient $\left[\mathrm{O}_{2}\right]$ values. For calculation of $C_{f}$ and $E_{\mathrm{max}}$ a generic flow velocity $u_{100}=2 \mathrm{~cm} \mathrm{~s}^{-1}$ is assumed. The $\Delta u_{100}$ is the change in flow velocity required to compensate (i.e., to keep $E_{\text {max }}$ constant) for a given increase in $T$ and the associated decrease in $\left[\mathrm{O}_{2}\right]$ due to the decrease in oxygen solubility with higher $T$ values. It represents the vulnerability of a given system to global change. Since $\left[\mathrm{O}_{2}\right]$ values are fairly low in our study area, $\Delta u_{100}$ values have been calculated with an assumed $T$ increase of only $0.05^{\circ} \mathrm{C}$.

profiles. Since $\left[\mathrm{O}_{2}\right]$ values are fairly low in our study area, $\Delta u_{100}$, the change in flow velocity required to compensate (i.e., to keep $E_{\max }$ constant) for a given warming and associated deoxygenation, has been calculated with an assumed $T$ increase by only $0.05^{\circ} \mathrm{C}$ as to not reach absolute zero $\left[\mathrm{O}_{2}\right]$ values and introduce further chemical complexity (Fig. 7, right panel). Down to about $600 \mathrm{~m}$, the system is fairly resistant to a $0.05^{\circ} \mathrm{C} T$ increase, but below that depth, even this very small $T$ increase and the associated $\left[\mathrm{O}_{2}\right]$ decrease would have to be compensated by free streamflow velocity increases of up to $\approx 1.5 \mathrm{~cm} \mathrm{~s}^{-1}$-almost double our assumed mean background value.

\section{c. Bottom water observations}

Depth and oxygenation show a tendency to be inversely related. Waters close to the relatively flat bottom of the basin at $\approx 900 \mathrm{~m}$ consistently showed the lowest
$\mathrm{pO}_{2}$ values of about 0.46 matm and $\left[\mathrm{O}_{2}\right]$ values of about $0.60 \mu \mathrm{mol} \mathrm{kg}^{-1}$ (Figs. 8 and 9: $\mathrm{pO}_{2}$; Fig. 10: $\left[\mathrm{O}_{2}\right]$ ). To the northwest of our survey area, the base of the Santa Monica Canyon is overflown by the AUV (dive 1) and both $\mathrm{pO}_{2}$ and $\left[\mathrm{O}_{2}\right]$ values are considerably higher $(>1.6$ matm and $>2 \mu \mathrm{mol} \mathrm{kg}^{-1}$ ) than at the bottom of the basin, consistent with shallower depths found at the base of the canyon. No localized point-source-processrelated $\mathrm{O}_{2}$ drawdown can be detected in the area covered by our dives. The seafloor rises toward the southeast (overflown in dive 2), consistently accompanied by higher oxygenation values. Water above the large mound to the south of our survey area, the base of which has been traversed in dive 3 in the west-southwest to east-northeast direction, shows higher oxygenation values consistent with its shallower depth.

In the area of the "Santa Monica mounds" (Paull et al. 2008), seafloor-methane-seepage-derived structures occur 


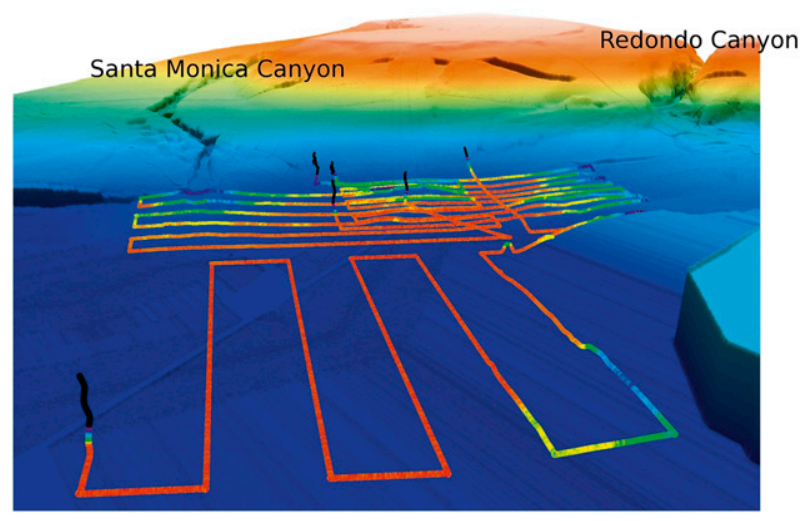

FIG. 8. A $3 \mathrm{D}$ view and horizontal distribution $\mathrm{pO}_{2}$ in the surveyed part of the Santa Monica Basin. This representation of the data is produced with the MBARI-developed software package MBGridViz (developed by David Caress) and helps to visually locate the chemical data $\left(\mathrm{pO}_{2}\right)$ in respect to the bathymetry of the survey area. In contrast to traditional hydrocasts that provide depth profiles of parameters in question (which our AUV-based method provides as well; see Figs. 3, 4, 5, etc.) or 2D maps plotted on density surfaces gridded from sparse single-point data, often not very close to the bottom, our method not only provides an easy visual correlation of the field of chemical data (here, $\mathrm{pO}_{2}$ ) with the bathymetry of the survey area, but also spatially very highly resolved data consistently about $10 \mathrm{~m}$ off the bottom and is thus ideally suited for high-resolution monitoring of areas of interest (e.g., nearshore hypoxic regions such as the Santa Monica Bay).

in the center of the surveyed area (northeast mound: $33.79913^{\circ} \mathrm{N}, 118.64682^{\circ} \mathrm{W}$, top of the mound $809-\mathrm{m}$ water depth; southwest mound: $33.78894^{\circ} \mathrm{N}, 118.66822^{\circ} \mathrm{W}$, top of the mound 863-m water depth), a generally consistent depth-versus-oxygenation relation can be observed, with the deeper southwest mound showing a $\mathrm{pO}_{2}$ of about 0.5 matm lower than the northeast mound and correspondingly, $\left[\mathrm{O}_{2}\right]$ is between 0.5 and $1 \mu \mathrm{mol} \mathrm{kg}-1$ lower on the southwest mound than on the northeast mound. Previous MBARI ROV video surveys of the summits of the two mounds show vastly different biological communities: at the shallower northeast summit, a dense population of clams and occasional crabs can be seen. At the slightly deeper southwest mound, only a white/yellow bacterial mat can be observed with a near-complete absence of higher life forms. It appears that these two sites may bracket the critical $\mathrm{pO}_{2}$ boundary for sustaining nonmicrobial aerobic marine life in the Santa Monica Basin.

$\left[\mathrm{NO}_{3}^{-}\right]$(Fig. 10, right panel) shows a clear relation with depth, spreading from values down to $\approx 25 \mu \mathrm{mol} \mathrm{kg}^{-1}$ in some locations on the flat basin floor at around 900-m depth up to $\approx 35 \mu \mathrm{mol} \mathrm{kg}^{-1}$ in the shallowest areas.

Three-dimensional representations of values of $T, S$, optical backscatter at $470 \mathrm{~nm}$ (bbp470) and $676 \mathrm{~nm}$ (bbp676), and colored dissolved organic matter concentration in engineering units CDOM (ECOfl), all largely consistent with depth, can be found in appendix B. Appendix B also contains $3 \mathrm{D}$ representations of values of the minimal oxygen concentration $C_{f}$ able to support a given oxygen consumption rate, the maximal oxygen consumption rate the environment is able to support $E_{\max }$, as well as the change in water velocity required to keep $E_{\max }$ constant $\left(\Delta u_{100}\right)$ under given warming and deoxygenation scenarios (Hofmann et al. 2011).

\section{Discussion}

The terms "hypoxic" and "suboxic" are traditionally used, but they often lack rigorous definitions (see Hofmann et al. 2010 for details). However, as climate change proceeds, we are very likely to also experience true ocean "anoxia." Detection of the emergence of anoxia, and showing that it is related to large-scale climate change, as well as local effects, is a critical problem, as full anoxia will bring with it locally the appearance of toxic $\mathrm{H}_{2} \mathrm{~S}$ in the water column [see Canfield et al. (2010) for an example of nascent $\mathrm{H}_{2} \mathrm{~S}$ emergence]. As significant ocean boundaries (or "tipping points") might be crossed, the ability to accurately survey present-day very low- $\mathrm{O}_{2}$ environments with high spatial resolution, technically difficult though it may be, is an important challenge. In that sense, the objective of the AUV survey was met in terms of producing high-quality, highresolution, three-dimensional maps of key hypoxia-, suboxia-, and anoxia-defining quantities $\left[\mathrm{O}_{2}\right], T, S, P$, and the supporting quantity $\left[\mathrm{NO}_{3}^{-}\right]$, as well as a variety of derived quantities providing additional information $\left(\mathrm{pO}_{2}\right.$, $\left.C_{f}, E_{\max }, \Delta u_{100}\right)$ in Santa Monica Basin bottom waters.

The survey tracks were arranged in such a fashion that the vehicle followed the terrain up and down through the water column for some tens of meters numerous times during one single dive of the survey. Gradients consistent with bathymetry were found and consistent values were obtained at depth between the three dives. Thus, it can be concluded that the $\left[\mathrm{O}_{2}\right]$ gradient from about 0.5 to $2.5 \mu \mathrm{mol} \mathrm{kg}^{-1}$ in the bottom waters of our survey was not instrument drift (e.g., because of $\mathrm{O}_{2}$ diffusion from polymeric materials or possible leakage of $\mathrm{O}_{2}$-rich waters from void spaces in the vehicle-as this influence decays quickly), but it is geographically consistent with depth (i.e., no "horizontal," non-depthrelated $\left[\mathrm{O}_{2}\right]$ gradient could be detected).

Furthermore, because of these observed terrainconsistent $\left[\mathrm{O}_{2}\right]$ profiles and because of the findings of other authors in similar circumstances (Thamdrup et al. 2012), which suggest that the oxygen sensors used here work well down to the $\left[\mathrm{O}_{2}\right]$ concentrations, we found (when there is sufficient time for any polymer fabricated 


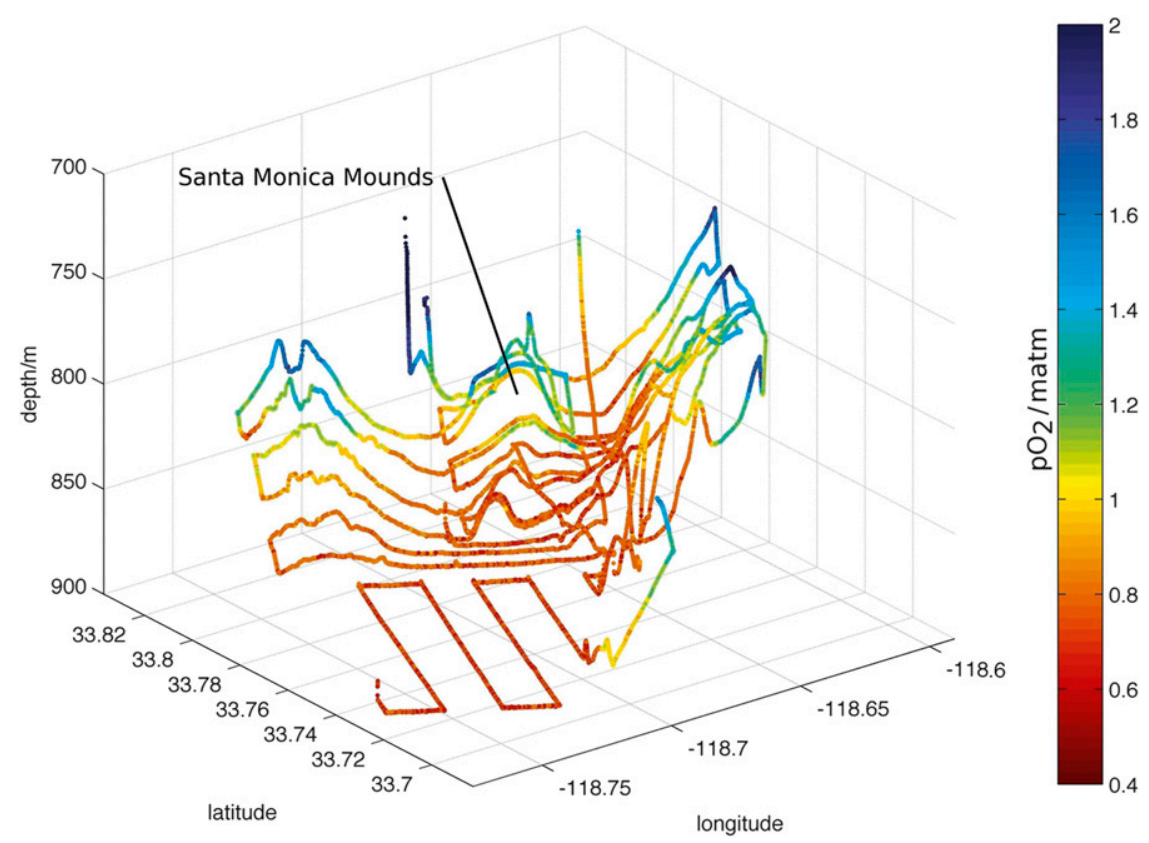

FIG. 9. A 3D view and horizontal distribution of the $\mathrm{pO}_{2}$ in the surveyed part of the Santa Monica Basin. This alternative representation of the data was produced with MATLAB and shows the data located in a latitude-longitude grid, using high vertical exaggeration (only the depth slice between 700- and 900-m depth is plotted), and not showing bathymetry as to enable a visually clearer impression of variations in the dataset.

parts close to the electrode to lose their dissolved $\mathrm{O}_{2}$-as was the case for our dives) we have a high confidence in the obtained absolute $\left[\mathrm{O}_{2}\right]$ values.

Around the area of the Santa Monica mounds (Paull et al.2008), roughly the center of our survey area, survey tracks of dive 1 and dive 2 overlapped. The $\left[\mathrm{O}_{2}\right]$ values, as well as $T$ and $S$ values (see appendix B), differ between those two dives around the exposed location of the northeast mound. This most likely is due to basin natural motions such as the "freely propagating basinscale topographic waves driven by the long-period upper water column fluctuations" (Hickey 1992, p. 37) that have been reported by Gregg and Kunze (1991) and characterized for the Santa Monica Basin by Hickey (1992). Similar differences were not observed at the deeper southwestern mound $\left(33.78894^{\circ} \mathrm{N}, 118.66822^{\circ} \mathrm{W}\right)$,
A

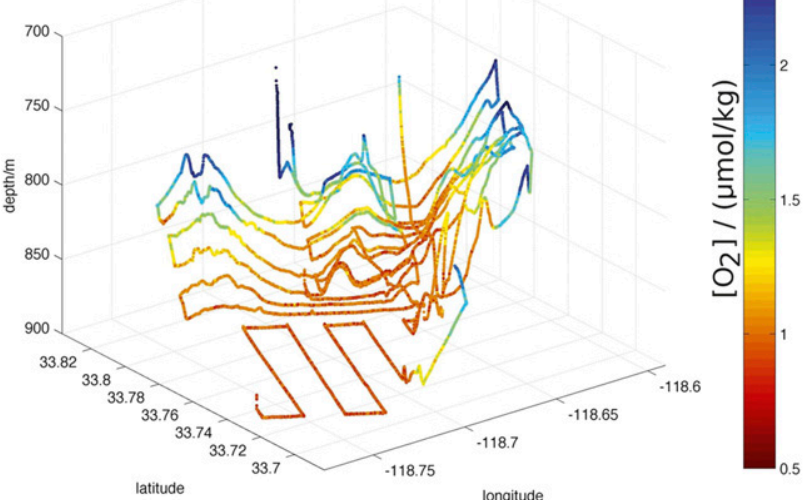

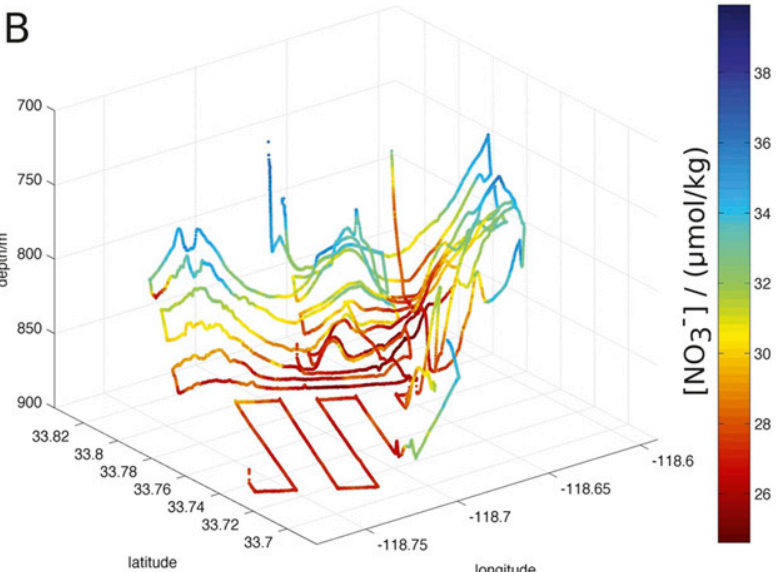

Iongitude

FIG. 10. A 3D view and horizontal distribution of (a) $\left[\mathrm{O}_{2}\right]$ and (b) $\left[\mathrm{NO}_{3}^{-}\right]$in the surveyed part of the Santa Monica Basin, as obtained from the AUV sensors. 
indicating more stable, nearly anoxic conditions-not to the same extent affected by basin-scale natural motions. Together with the marked differences in observed biological communities at the two mounds mentioned above, this supports the notion that, on medium time scales, the southwestern mound stays below the critical $\mathrm{pO}_{2}$ boundary of sustenance for most aerobic marine life in the Santa Monica Basin, while the northeastern mound remains above this threshold and is even periodically flushed with higher oxygen waters.

The $\left[\mathrm{O}_{2}\right]$ values in the Santa Monica Basin were very low during our survey. Oxygenation values of waters as shallow as $\approx 50 \mathrm{~m}$ could already be described as mildly hypoxic (hypoxia category A in Hofmann et al. 2011). From $\approx 100 \mathrm{~m}$ down to the bottom, the Santa Monica Basin oxygenation was below the Gulf of Mexico "dead zone" threshold (Turner et al. 2008; Lumcon 2010), or hypoxia category B in Hofmann et al. (2011). Oxygenation below $\approx 300 \mathrm{~m}$ was also below the hypoxia category C threshold in Hofmann et al. (2011), where only highly specialized species are able to survive and mass mortality for most nonadapted species is induced if they are suddenly exposed to such low-oxygen conditions (Diaz and Rosenberg 2008; Riedel et al. 2008; Haselmair et al. 2010). Hofmann et al. (2011) characterize the likelihood of a parcel of low-oxygen water transported onto the shelf by upwelling events with $\Delta \sigma_{\theta}$, its distance from the 200-m isobath (used as a generic limit of the continental shelf) in terms of potential density, which is proportional to the potential energy difference between the respective waters and shelf depths. The $\Delta \sigma_{\theta}$ for hypoxia category $\mathrm{C}$ waters $\left(\mathrm{pO}_{2}<22\right.$ matm) in the Santa Monica Basin is about $0.1276 \mathrm{~kg} \mathrm{~m}^{-3}$, which is only about one-fourth of the $\Delta \sigma_{\theta}$ for hypoxia category C values of $\approx 0.45 \mathrm{~kg} \mathrm{~m}^{-3}$ for waters off the coast of Oregon (Hofmann et al. 2011), for which dramatic ecosystem-wide impacts of upwelling-induced hypoxia have already been reported (Grantham et al. 2004; Chan et al. 2008). Local wind-driven coastal upwelling has already been documented for the Santa Monica Bay shelf (Hickey et al. 2003; Allen and Hickey 2010), and it might lead to serious negative impacts on fisheries and coastal recreation in the future, especially since hypoxia boundaries are already shoaling and fisheries are declining in the California Current (Koslow et al. 2011) and are likely to shoal farther in the future.

The bottom waters of the Santa Monica Basin showed oxygen values well into the onset of the suboxic zone, traditionally defined as below $10 \mu \mathrm{mol} \mathrm{kg}^{-1}$ and even below the stronger threshold of $5 \mu \mathrm{mol} \mathrm{kg}{ }^{-1}$ used to describe suboxic environments, where microbial utilization of nitrate as an electron acceptor is well underway (Rue et al. 1997). At a depth of $650 \mathrm{~m}$ and below, evidence of $\mathrm{NO}_{3}^{-}$loss with continuing $\mathrm{O}_{2}$ consumption could be clearly observed, even though a nitrite peak could not be detected likely because of very rapid oxidation of produced $\mathrm{NO}_{2}^{-}$, consistent with suboxic but nonzero $\mathrm{O}_{2}$ conditions (Thamdrup et al. 2012). Hydrogen sulfide (bisulfide) was not detected in our 10-mabove-bottom survey. This is consistent with the concept that both $\mathrm{O}_{2}$ (Stolper et al. 2010) and $\left[\mathrm{NO}_{3}^{-}\right]$near zero must be achieved before sulfide emergence can be detected (Canfield et al. 2005).

\section{Conclusions and outlook}

The work reported here was executed from a small (26 $\mathrm{m}$ long) ship in only three dive days with a scientific party of four. This raises the prospect of more timely and cost-effective monitoring of expanding hypoxia over complex terrain as longer-range vehicles [e.g., the MBARI long-range AUV (LRAUV) "Tethys"; Bellingham et al. 2010; Godin et al. 2010; Y. Zhang et al. 2010] and enhanced, low-power, and stable in situ chemical sensors appear. Although the survey took place within a relatively well-defined basin, the presence of very different slope gradients and of prominent mounds provided sufficient challenges that one can say with reasonable confidence that chemical mapping AUV missions over complex seafloor topography are possible. The ability to map chemical fields over the topography can indicate where finescale biological gradients may be observed and interpreted. For future AUV missions with the same configuration, it is desirable to obtain enough Gulper water samples to calculate high-quality correcting offsets for ISUS $\left[\mathrm{NO}_{3}^{-}\right]$data for all dives.

The focus here was on defining the bottom water chemical conditions supporting benthic marine life, since this is where the disparity between modern highresolution seafloor mapping and widely spaced hydrographic surveys is greatest. In the Santa Monica Basin, we mapped bottom waters that are far below the usual hypoxia and even suboxic definitions, posing serious limitations to aerobic life. In the bottom water, we found no depth-independent horizontal gradient in $\left[\mathrm{O}_{2}\right]$ on the same order of magnitude of the depth-related gradients we found (1-2 $\mu \mathrm{mol} \mathrm{kg}^{-1}$ ) that would suggest a local contribution of anthropogenic point-source-related processes to the low-oxygen conditions.

It is well established that ocean warming from climate change is occurring, and that this will lower oceanic oxygen levels both from the direct solubility effect and from increased microbial respiration rates with harmful effects on aerobic marine life. Thus, the precise definition and mapping of hypoxic ocean regions will be in demand, as will the ability to separate "normal" 

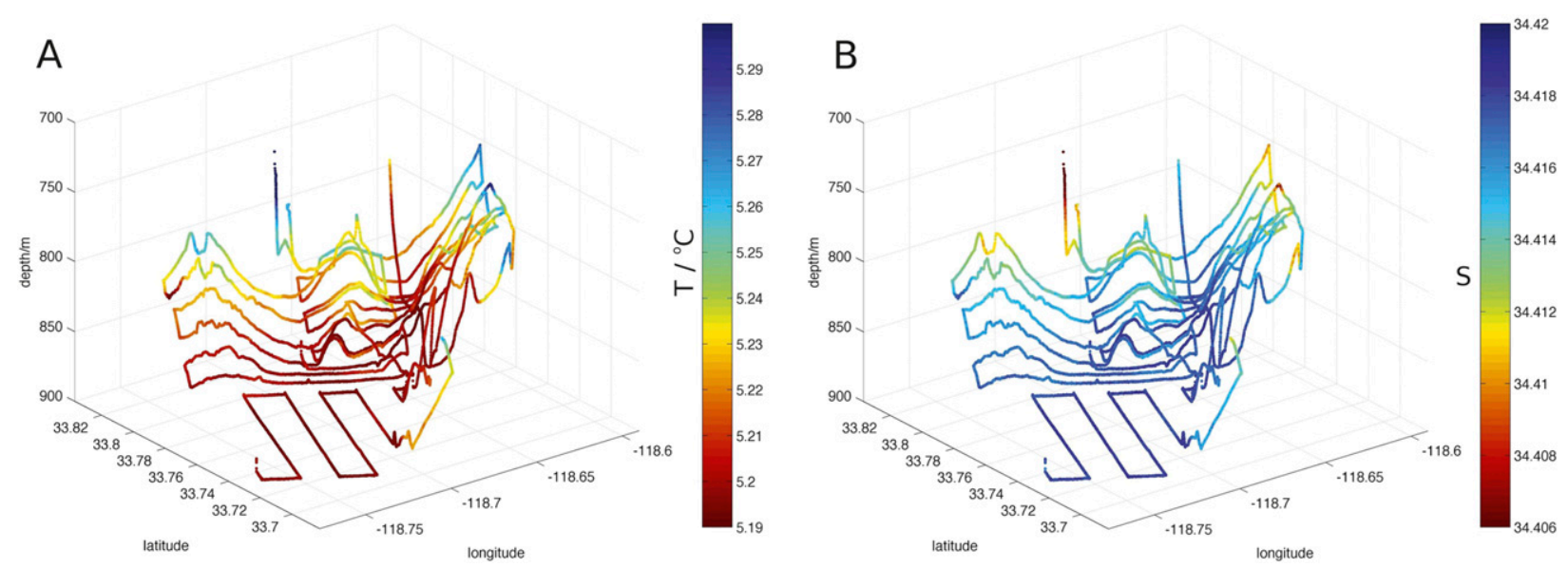

FIG. B1. A 3D view and horizontal distribution of plots of (a) $T$ and (b) $S$ in the surveyed part of the Santa Monica Basin, as obtained from the AUV sensors.

fluctuations from long-term trends, and the ability to separate locally driven hypoxia from riverine input, etc., from more general trends. As low-oxygen regions expand, the marked associations between topography, flow, and chemical signals will need further careful interpretation.

Acknowledgments. This work was supported by a grant to the Monterey Bay Aquarium Research Institute from the David and Lucile Packard Foundation. We thank the AUV specialist Doug Conlin and the crew of the R/V Zephyr, headed by Captain Aaron Gregg, for the flawless execution of the cruise and the AUV dives; Mike McCann and John Ryan for their help with data processing; Carole Sakamoto for her help with reprocessing ISUS nitrate data; David Caress for his help with 3D visualization of the data; and Marguerite Blum for processing Gulper water samples in the laboratory.

\section{APPENDIX A}

\section{$\left[\mathrm{NO}_{3}^{-}\right]$Data Postprocessing}

Absolute concentration values obtained with the ISUS instrument can be influenced by, among others, fouling of the optics and changes in internal light throughput in the instrument, which can create offsets in the absolute concentration output of the sensor. Often, these offsets develop during the periods when the AUV is on deck-that is, between dives, for examplebecause of a film drying on the optics that creates a slight shift in absorbance. As a result, we have found that these offsets are essentially constant over long stretches of the profile of each dive, often over the whole dive, so adjusting the offsets in the $\left[\mathrm{NO}_{3}^{-}\right]$values with discrete data is an accepted practice (see also Johnson et al. 2010). Here, for dives 1 and 2 discrete $\left[\mathrm{NO}_{3}^{-}\right]$values

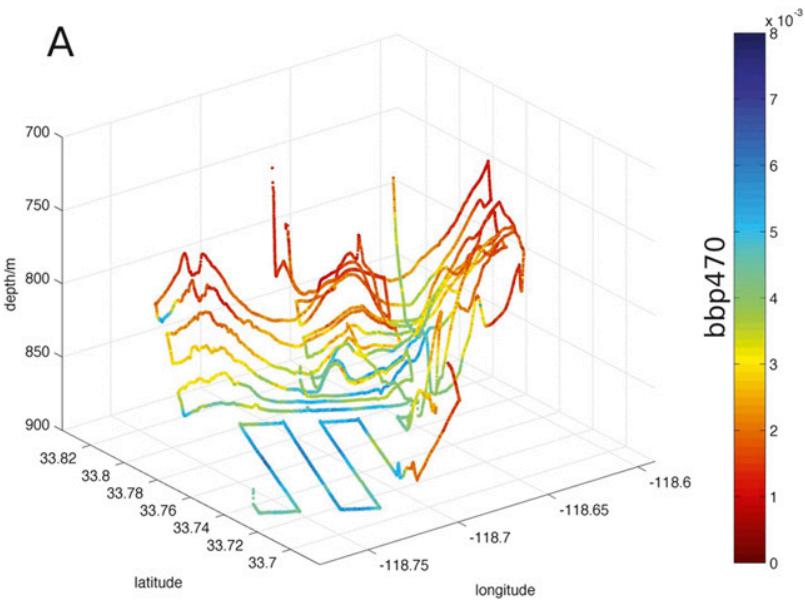

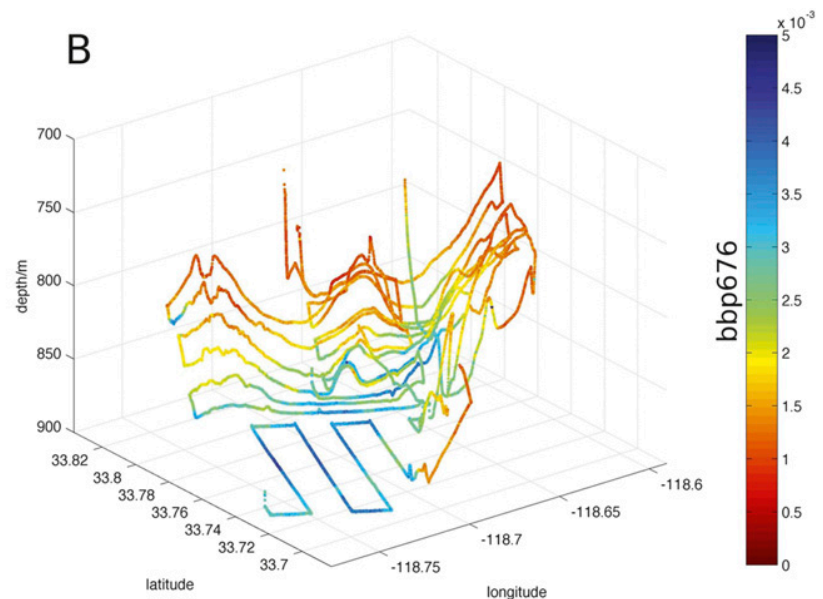

FIG. B2. A 3D view and horizontal distribution of plots of optical backscatter (a) bbp470 and (b) bbp676 in the surveyed part of the Santa Monica Basin, as obtained from the AUV sensors. Values are on engineering units. 

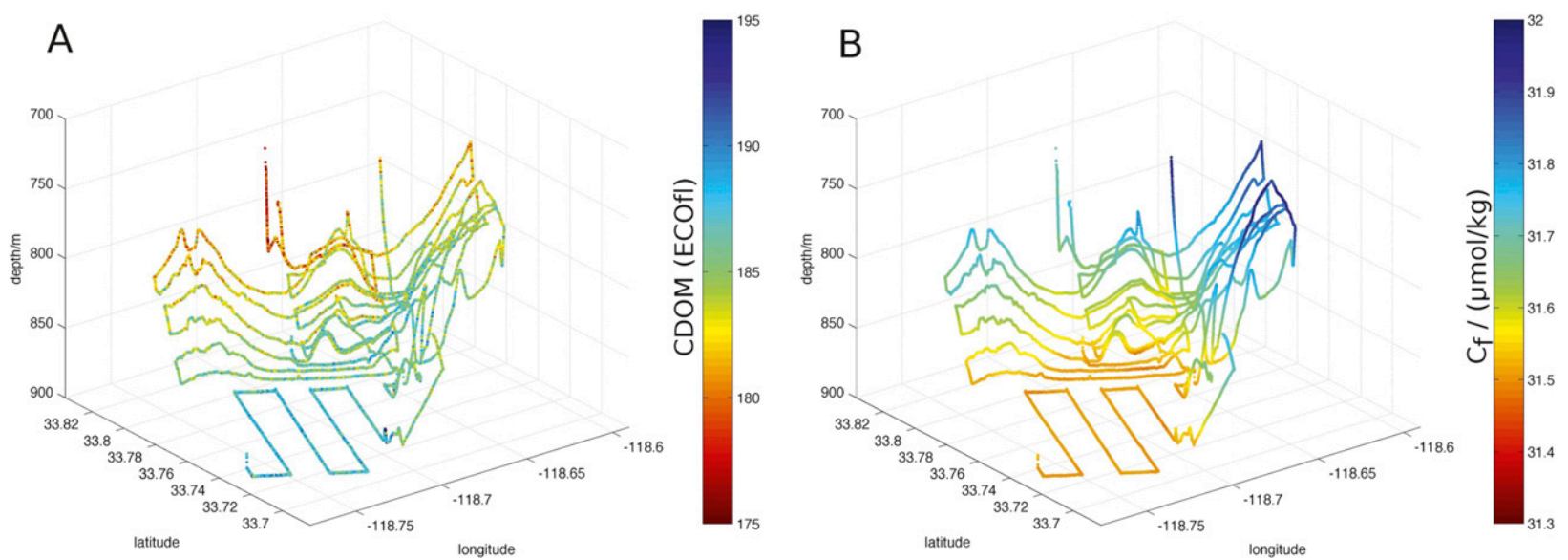

FIG. B3. (a) A 3D view and horizontal distribution of plots of CDOM-ECOfl in the surveyed part of the Santa Monica Basin, as obtained from the AUV sensors (values on engineering units). (b) 3D view and horizontal distribution of $C_{f}$, a quantity to describe the hospitability for aerobic organisms according to Hofmann et al. (2012); $C_{f}$ is the $\left[\mathrm{O}_{2}\right]$ value the free stream water must minimally have to sustain a given oxygen uptake rate $E$ (we use a generic example value of $E=20 \times 10^{-7} \mu \mathrm{mols}^{-1} \mathrm{~cm}^{-2}$ here). It represents the influence of $T, S$, and pressure on oxygen uptake rates. For calculation of $C_{f}$, a generic flow velocity $u_{100}=2 \mathrm{~cm} \mathrm{~s}^{-1}$ is assumed.

obtained from laboratory analysis of the Gulper water samples were used to calculate a linear compensation in the absolute concentration response of the sensor. For each laboratory data point, a set of maximally 10 ISUS data points that are closest in terms of potential density has been averaged and an offset to the laboratory value has been calculated. Offsets for available laboratory data points have been averaged to obtain linear offset values for each dive: $\approx 3.56 \mu \mathrm{mol} \mathrm{kg}^{-1}$ for dive 1 and $\approx 2.61 \mu \mathrm{mol} \mathrm{kg}^{-1}$ for dive 2 (note that throughout this publication, the concentration unit " $\mathrm{kg}^{-1}$ ", refers to per-kilogram solution). For dive 3 , an offset of $\approx-0.45 \mu \mathrm{mol} \mathrm{kg}^{-1}$ has been calculated. However, there were only three laboratory data points available for dive 3 (because of a premature shutdown of the vehicle due to empty batteries during the ascending phase where Gulper samples were taken) and all of those points were below $700 \mathrm{~m}$, where $\left[\mathrm{NO}_{3}^{-}\right]$ variability was highest, resulting in inaccurate offset calculation. Therefore, and because of the small calculated value of the offset, we choose not to apply an offset to $\left[\mathrm{NO}_{3}^{-}\right]$values from dive 3 . As there seems to be a trend in offsets toward smaller values, an offset around zero
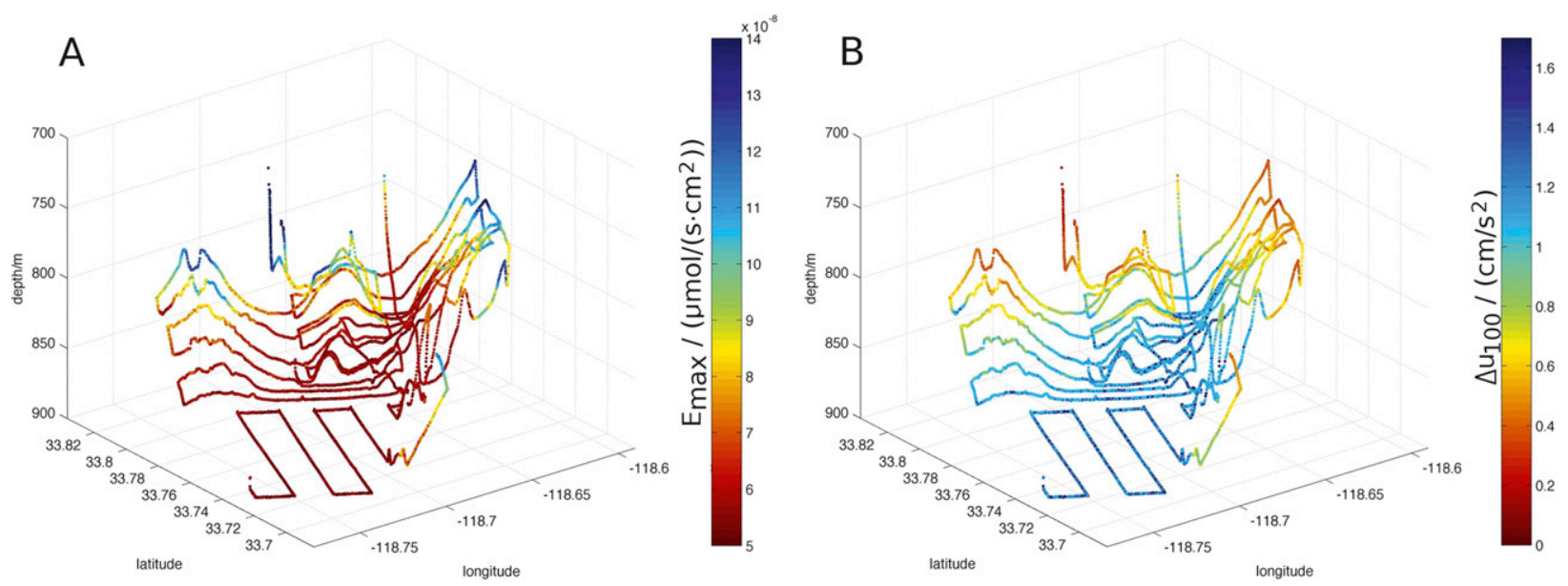

FIG. B4. A 3D view and horizontal distribution of plots two other quantities according to Hofmann et al. (2012) representing the hospitability of an oceanic environment to aerobic life: (a) The term $E_{\max }$ represents the maximal oxygen uptake rate the given environment is capable of sustaining. It combines effects of $T, S$, and pressure with ambient $\left[\mathrm{O}_{2}\right]$ values. For calculation of $E_{\max }$, a generic flow velocity $u_{100}=2 \mathrm{~cm} \mathrm{~s}^{-1}$ is assumed. (b) The $\Delta u_{100}$ is the change in flow velocity required to compensate (i.e., to keep $E_{\max }$ constant) for a given increase in $T$ and the associated decrease in $\left[\mathrm{O}_{2}\right]$ due to the decrease in oxygen solubility with higher $T$ values. It represents the vulnerability of a given system to global change. Since $\left[\mathrm{O}_{2}\right]$ values are fairly low in our study area, $\Delta u_{100}$ values have been calculated with an assumed $T$ increase of only $0.05^{\circ} \mathrm{C}$. 
for dive 3 is plausible. The differences between $\left[\mathrm{NO}_{3}^{-}\right]$ in dives 1, 2, and 3 are analyzed and discussed in section $4 \mathrm{a}$.

\section{APPENDIX B}

\section{Additional Figures}

Figures B1-B4 contain additional 3D representations of data measured during the AUV mission or derived from data measured during the AUV mission.

\section{REFERENCES}

Allen, S. E., and B. M. Hickey, 2010: Dynamics of advection-driven upwelling over a shelf break submarine canyon. J. Geophys. Res., 115, C08018, doi:10.1029/2009JC005731.

Bellingham, J. G., K. Streitlien, J. Overland, S. Rajan, P. Stein, J. Stannard, W. Kirkwood, and D. Yoerger, 2000: An arctic basin observational capability using AUVs. Oceanography, 13 (2), 64-71.

— and Coauthors, 2010: Efficient propulsion for the Tethys long-range autonomous underwater vehicle. Proc. 2010 IEEE/ OES Autonomous Underwater Vehicles (AUV), Monterey, CA, IEEE, doi:10.1109/AUV.2010.5779645.

Bird, L. E., A. D. Sherman, and J. P. Ryan, 2007: Development of an active, large volume, discrete seawater sampler for autonomous underwater vehicles. Proc. Oceans 2007 MTS/IEEE, Vancouver, BC, Canada, IEEE, doi:10.1109/OCEANS.2007.4449303.

Bograd, S. J., F. B. Schwing, C. G. Castro, and D. A. Timothy, 2002: Bottom water renewal in the Santa Barbara Basin. J. Geophys. Res., 107, 3216, doi:10.1029/2001JC001291.

—, C. G. Castro, E. Di Lorenzo, D. M. Palacios, H. Bailey, W. Gilly, and F. P. Chavez, 2008: Oxygen declines and the shoaling of the hypoxic boundary in the California Current. Geophys. Res. Lett., 35, L12607, doi:10.1029/2008GL034185.

Camilli, R., and Coauthors, 2010: Tracking hydrocarbon plume transport and biodegradation at Deepwater Horizon. Science, 330, 201-204, doi:10.1126/science.1195223.

Canfield, D. E., B. Thamdrup, and E. Kristensen, 2005: Aquatic Geomicrobiology. Advances in Marine Biology, Vol. 48, Elsevier Academic, $656 \mathrm{pp}$.

— , F. J. Stewart, B. Thamdrup, L. De Brabandere, T. Dalsgaard, E. F. Delong, N. P. Revsbech, and O. Ulloa, 2010: A cryptic sulfur cycle in oxygen-minimum-zone waters off the Chilean coast. Science, 330, 1375-1378, doi:10.1126/science.1196889.

Caress, D. W., and Coauthors, 2008: High-resolution multibeam, sidescan, and subbottom surveys using the MBARI AUV D. Allan B. Marine Habitat Mapping Technology for Alaska, J. R. Reynolds and H. G. Greene, Eds., Alaska Sea Grant College Program, University of Alaska Fairbanks, 47-70, doi:10.4027/mhmta.2008.04.

—, D. A. Clague, J. B. Paduan, J. F. Martin, B. M. Dreyer, W. W. Chadwick, A. Denny, and D. S. Kelley, 2012: Repeat bathymetric surveys at 1-metre resolution of lava flows erupted at axial seamount in April 2011. Nat. Geosci., 5, 483-488, doi:10.1038/ngeo1496.

Chan, F., J. A. Barth, J. Lubchenco, A. Kirincich, H. Weeks, W. T. Peterson, and B. A. Menge, 2008: Emergence of anoxia in the
California Current large marine ecosystem. Science, 319, 920, doi:10.1126/science.1149016.

Childress, J. J., and B. A. Seibel, 1998: Life at stable low oxygen levels: Adaptations of animals to oceanic oxygen minimum layers. J. Exp. Biol., 201, 1223-1232.

Connolly, T. P., B. M. Hickey, S. L. Geier, and W. P. Cochlan, 2010: Processes influencing seasonal hypoxia in the northern California Current System. J. Geophys. Res., 115, C03021, doi:10.1029/2009JC005283.

Diaz, R. J., and R. Rosenberg, 2008: Spreading dead zones and consequences for marine ecosystems. Science, 321, 926-929.

Ekau, W., H. Auel, H.-O. Pörtner, and D. Gilbert, 2010: Impacts of hypoxia on the structure and processes in pelagic communities (zooplankton, macro-invertebrates and fish). Biogeosciences, 7, 1669-1699, doi:10.5194/bg-7-1669-2010.

Emery, K. O., 1960: The Sea Off Southern California: A Modern Habitat of Petroleum. John Wiley \& Sons, Inc., 366 pp.

Enns, T., P. F. Scholander, and E. D. Bradstreet, 1965: Effect of hydrostatic pressure on gases dissolved in water. J. Phys. Chem., 69, 389-391.

Garcia, H. E., and L. I. Gordon, 1992: Oxygen solubility in seawater: Better fitting equations. Limnol. Oceanogr., 37, 13071312.

Godin, M. A., J. G. Bellingham, B. Kieft, and R. McEwen, 2010: Scripting language for state configured layered control of the Tethys long range autonomous underwater vehicle. Proc. Oceans 2010 MTS/IEEE, Seattle, WA, IEEE, doi:10.1109/ OCEANS.2010.5664515.

Gooday, A. J., F. Jorissen, L. A. Levin, J. J. Middelburg, S. W. A. Naqvi, N. N. Rabalais, M. Scranton, and J. Zhang, 2009: Historical records of coastal eutrophication-induced hypoxia. Biogeosciences, 6, 1707-1745.

Grantham, B. A., F. Chan, K. J. Nielsen, D. S. Fox, J. A. Barth, A. Huyer, J. Lubchenco, and B. A. Menge, 2004: Upwellingdriven nearshore hypoxia signals ecosystem and oceanographic changes in the northeast Pacific. Nature, 429, 749-754.

Gregg, M. C., and E. Kunze, 1991: Shear and strain in Santa Monica Basin. J. Geophys. Res., 96 (C9), 16709-16719.

Haselmair, A., M. Stachowitsch, M. Zuschin, and B. Riedel, 2010: Behaviour and mortality of benthic crustaceans in response to experimentally induced hypoxia and anoxia in situ. Mar. Ecol. Prog. Ser., 414, 195-208.

Helm, K. P., N. L. Bindoff, and J. A. Church, 2011: Observed decreases in oxygen content of the global ocean. Geophys. Res. Lett., 38, L23602, doi:10.1029/2011GL049513.

Hickey, B. M., 1991: Variability in two deep coastal basins (Santa Monica and San Pedro) off Southern California. J. Geophys. Res., 96 (C9), 16 689-16708.

, 1992: Circulation over the Santa Monica-San Pedro Basin and shelf. Prog. Oceanogr., 30, 37-115, doi:10.1016/ 0079-6611(92)90009-O.

— E. L. Dobbins, and S. E. Allen, 2003: Local and remote forcing of currents and temperature in the central Southern California Bight. J. Geophys. Res., 108, 3081, doi:10.1029/ 2000JC000313.

Hofmann, A. F., K. Soetaert, J. J. Middelburg, and F. J. R. Meysman, 2010: AquaEnv: An aquatic acid-base modelling environment in R. Aquat. Geochem., 16, 507-546.

— E. T. Peltzer, P. M. Walz, and P. G. Brewer, 2011: Hypoxia by degrees: Establishing definitions for a changing ocean. DeepSea Res. I, 58, 1212-1226, doi:10.1016/j.dsr.2011.09.004. 
,-- , and P. G. Brewer, 2012: Kinetic bottlenecks to chemical exchange rates for deep-sea animals-Part 1: Oxygen. Biogeosci. Discuss., 9, 13817-13856.

Johnson, K. S., and L. J. Coletti, 2002: In situ ultraviolet spectrophotometry for high resolution and long-term monitoring of nitrate, bromide and bisulfide in the ocean. Deep-Sea Res. I, 49, 1291-1305, doi:10.1016/S0967-0637(02)00020-1.

_ plankton metabolism using nitrate and oxygen sensors on an autonomous underwater vehicle. Limnol. Oceanogr., 53, 2237-2250.

— S. C. Riser, and D. M. Karl, 2010: Nitrate supply from deep to near-surface waters of the North Pacific subtropical gyre. Nature, 465, 1062-1065, doi:10.1038/nature09170.

Kirkwood, W. J., 2007: Development of the DORADO mapping vehicle for multibeam, subbottom, and sidescan science missions. J. Field Rob., 24, 487-495.

Koslow, J., R. Goericke, A. Lara-Lopez, and W. Watson, 2011: Impact of declining intermediate-water oxygen on deepwater fishes in the California Current. Mar. Ecol. Prog. Ser., 436, 207-218.

Levin, L. A., and Coauthors, 2009: Effects of natural and humaninduced hypoxia on coastal benthos. Biogeosciences, 6, 2063 2098.

Lumcon, 2010: 2010 dead zone-One of the largest ever. Lumcon news release. [Available online at http://www. lumcon.edu/Information/news/default.asp?XMLFilename $=$ 201007311451.xml.]

Maier, K. L., A. Fildani, C. K. Paull, S. A. Graham, T. R. McHargue, D. W. Caress, and M. McGann, 2011: The elusive character of discontinuous deep-water channels: New insights from Lucia Chica channel system, offshore California. Geology, 39, 327-330, doi:10.1130/G31589.1.

Masiello, C. A., and E. R. M. Druffel, 2003: Organic and black carbon super ${ }^{13} \mathrm{C}$ and ${ }^{14} \mathrm{C}$ through the Santa Monica Basin sediment oxic-anoxic transition. Geophys. Res. Lett., 30, 1185, doi:10.1029/2002GL015050.

McClatchie, S., and Coauthors, 2009: The state of the California Current, spring 2008-2009: Cold conditions drive regional differences. California Cooperative Oceanic Fisheries Investigations Rep. 50, 43-69.

—, R. Goericke, R. Cosgrove, G. Auad, and R. Vetter, 2010: Oxygen in the Southern California Bight: Multidecadal trends and implications for demersal fisheries. Geophys. Res. Lett., 37, L19602, doi:10.1029/2010GL044497.

Mearns, A. J., and L. Smith, 1976: Benthic oceanography and the distribution of bottom fish off Los Angeles. California Cooperative Oceanic Fisheries Investigations Rep. 18, 118-124.

Middelburg, J. J., and L. A. Levin, 2009: Coastal hypoxia and sediment biogeochemistry. Biogeosciences, 6, 1273-1293.

Nakanowatari, T., K. I. Ohshima, and M. Wakatsuchi, 2007: Warming and oxygen decrease of intermediate water in the northwestern North Pacific, originating from the Sea of Okhotsk, 1955-2004. Geophys. Res. Lett., 34, L04602, doi:10.1029/2006GL028243.

Paull, C. K., W. R. Normark, W. Ussler III, D. W. Caress, and R. Keaten, 2008: Association among active seafloor deformation, mound formation, and gas hydrate growth and accumulation within the seafloor of the Santa Monica Basin, offshore California. Mar. Geol., 250, 258-275, doi:10.1016/j.margeo.2008.01.011.

Riedel, B., M. Zuschin, A. Haselmair, and M. Stachowitsch, 2008: Oxygen depletion under glass: Behavioural responses of benthic macrofauna to induced anoxia in the northern
Adriatic. J. Exp. Mar. Biol. Ecol., 367, 17-27, doi:10.1016/ j.jembe.2008.08.007.

Rue, E., G. Smith, G. Cutter, and K. Bruland, 1997: The response of trace element redox couples to suboxic conditions in the water column. Deep-Sea Res. I, 44, 113-134.

Ryan, J. P., and Coauthors, 2010: Mobile autonomous process sampling within coastal ocean observing systems. Limnol. Oceanogr. Methods, 8, 394-402.

_ , Y. Zhang, H. Thomas, E. V. Rienecker, R. K. Nelson, and S. R. Cummings, 2011: A high-resolution survey of a deep hydrocarbon plume in the Gulf of Mexico during the 2010 Macondo blowout. Monitoring and Modeling the Deepwater Horizon Oil Spill: A Record-Breaking Enterprise, Geophys. Monogr., Vol. 195, Amer. Geophys. Union, 63-75, doi:10.1029/ 2011 GM001106.

Sakamoto, C. M., G. E. Friederich, and L. A. Codispoti, 1990: MBARI procedures for automated nutrient analyses using a modified Alpkem Series 300 Rapid Flow Analyzer. MBARI Tech. Rep. 90-2. [Available online at http://aquaticcommons. org/1971/1/Technical_Report_90-2.pdf.]

_ K. K. Johnson, and L. J. Coletti, 2009: Improved algorithm for the computation of nitrate concentrations in seawater using an in situ ultraviolet spectrophotometer. Limnol. Oceanogr. Methods, 7, 132-143.

Seibel, B. A., 2011: Critical oxygen levels and metabolic suppression in oceanic oxygen minimum zones. J. Exp. Biol., 214, 326-336.

Shaffer, G., S. M. Olsen, and J. O. P. Pedersen, 2009: Long-term ocean oxygen depletion in response to carbon dioxide emissions from fossil fuels. Nat. Geosci., 2, 105-109, doi:10.1038/ NGEO420.

Sibenac, M., W. Kirkwood, R. McEwen, F. Shane, R. Henthorn, D. Gashler, and H. Thomas, 2002: Modular AUV for routine deep water science operations. Oceans '02 MTS/IEEE, Vol. 1, 167-172, doi:10.1109/OCEANS.2002.1193266.

Stansfield, K., and Coauthors, 2001: Deep-sea, high-resolution, hydrography and current measurements using an autonomous underwater vehicle: The overflow from the Strait of Sicily. Geophys. Res. Lett., 28, 2645-2648.

Stolper, D. A., N. P. Revsbech, and D. E. Canfield, 2010: Aerobic growth at nanomolar oxygen concentrations. Proc. Natl. Acad. Sci. USA, 107, 18755-18760.

Stramma, L., G. C. Johnson, J. Sprintall, and V. Mohrholz, 2008: Expanding oxygen-minimum zones in the tropical oceans. Science, 320, 655-658.

Thamdrup, B., T. Dalsgaard, and N. P. Revsbech, 2012: Widespread functional anoxia in the oxygen minimum zone of the eastern South Pacific. Deep-Sea Res. I, 65, 36-45.

Turner, R. E., N. N. Rabalais, and D. Justic, 2008: Gulf of Mexico hypoxia: Alternate states and a legacy. Environ. Sci. Technol., 42, 2323-2327, doi:10.1021/es071617k.

Yoerger, D. R., M. Jakuba, A. M. Bradley, and B. Bingham, 2007: Techniques for deep sea near bottom survey using an autonomous underwater vehicle. Int. J. Rob. Res., 26, 41-54, doi: $10.1177 / 0278364907073773$.

Zhang, J., and Coauthors, 2010: Natural and human-induced hypoxia and consequences for coastal areas: Synthesis and future development. Biogeosciences, 7, 1443-1467, doi:10.5194/ bg-7-1443-2010.

Zhang, Y., J. G. Bellingham, M. Godin, J. P. Ryan, R. McEwen, B. Kieft, B. Hobson, and T. Hoover, 2010: Thermocline tracking based on peak-gradient detection by an autonomous underwater vehicle. Proc. Oceans 2010 MTS/IEEE, Seattle, WA, IEEE, doi:10.1109/OCEANS.2010.5664545. 